\title{
Comparison of two gas-phase chemical kinetic mechanisms of ozone formation over Europe
}

\author{
Youngseob Kim · Karine Sartelet • Christian Seigneur
}

Received: 19 October 2009 / Accepted: 18 December 2009 /

Published online: 23 January 2010

(C) The Author(s) 2010. This article is published with open access at Springerlink.com

\begin{abstract}
Two recent gas-phase chemical kinetic mechanisms for tropospheric ozone formation, one based on the lumped-structure approach (CB05) and the other based on the lumped-molecule approach (RACM2), are compared for simulations of ozone over Europe. The host air quality model is POLAIR3D of the Polyphemus modeling platform. A one-month period (15 July to 15 August 2001) is simulated. Model performance is satisfactory with both mechanisms. Overall, the two mechanisms give similar results with a domain-averaged difference of $3 \mathrm{ppb}$ and a mean fractional absolute difference of $5 \%$ (values averaged over the month for the daily 8 -h average maximum ozone concentrations). This difference results from different treatments in the two mechanisms for both inorganic and organic chemistry. Differences in the treatment of the inorganic chemistry are due mainly to differences in the kinetics of two reactions: $\mathrm{NO}+\mathrm{O}_{3} \longrightarrow \mathrm{NO}_{2}+\mathrm{O}_{2}$ and $\mathrm{NO}+\mathrm{HO}_{2} \longrightarrow \mathrm{NO}_{2}+\mathrm{OH}$. These differences lead to a domain-averaged difference in ozone concentration of $5 \%$, with RACM2 kinetics being more conducive to ozone formation. Differences in the treatment of organic chemistry lead to a domain-averaged difference in ozone concentration of $3 \%$, with CB05 chemistry being more conducive to ozone formation. This average difference results in part from compensating effects among various VOC classes and some significant differences are identified at specific locations (the coastline of northern Africa and eastern Europe: 9\%) and for specific organic classes (aldehydes, biogenic alkenes and aromatics). Differences in the treatment of the organic chemistry result from various aspects. For some VOC classes, such as aldehydes and biogenic alkenes, the more detailed explicit treatments using more model species in RACM2 lead to either greater or lower reactivity depending on
\end{abstract}

Y. Kim $(\bowtie) \cdot$ K. Sartelet $\cdot$ C. Seigneur

CEREA, Joint Laboratory École des Ponts ParisTech / EDF R\&D,

Université Paris-Est, 77455 Champs sur Marne, France

e-mail:kimy@cerea.enpc.fr 
the assumptions made for the oxidation products. For other VOC species, such as aromatics, the assumptions made about the major chemical oxidation pathways (aromatic alcohol formation in CB05 vs. ring opening in RACM2) affect the ozone formation significantly. Reconciliation of different chemical kinetic mechanisms will require experimental data to reduce current uncertainties in the kinetic (e.g., NO oxidation) and mechanistic (e.g., aromatics oxidation) representations of major chemical pathways.

Keywords Air quality modeling • Chemical mechanism • Ozone • CB05 - RACM2

\section{Introduction}

The gas-phase chemical mechanisms are an important component of air quality models (AQMs), because secondary pollutants such as ozone and particulate matter are formed during the gas-phase degradation of anthropogenic and biogenic compounds (Seinfeld and Pandis 1998; Finlayson-Pitts and Pitts 2000). A mechanism that treats oxidant formation explicitly would require several millions of organic reactants and products and even more reactions (Aumont et al. 2005). Hence the chemical mechanisms used in three-dimensional AQMs must strike a balance between the complexity of the mechanism and its computational efficiency (Dodge 2000). For example, Dennis et al. (1996) showed that the majority of the computing time for tropospheric gas-phase modeling ( 80 to $90 \%$ ) was consumed integrating the chemical rate equations. Condensing a chemical kinetic mechanism to minimize computational requirements necessarily introduces approximations that are reflected as uncertainties in the mechanism simulations. Therefore, it is useful to compare different chemical mechanisms implemented in AQMs and assess their influence on the predictions of AQMs. Several previous studies have been dedicated to the comparisons of the chemical mechanisms implemented in AQMs (Kuhn et al. 1998; Junier et al. 2005; Arteta et al. 2006; Faraji et al. 2008; Luecken 2008; Luecken et al. 2008; Pan et al. 2008; Sarwar et al. 2008). Most comparisons have addressed applications to North America or box model (0D) simulations; only one comparison over Europe was identified (Arteta et al. 2006). Reported ozone differences among chemical mechanisms vary from less than $1 \%$ to $8 \%$ over the whole calculation domain.

We examine here differences in ozone concentrations simulated with two recent chemical mechanisms, CB05 and RACM2. The mechanisms were incorporated within a three-dimensional (3-D) AQM, which was applied over Europe. First, a brief description of the models used in this study is given, including the chemical mechanisms, the host air quality model, the modeling domain, model setup and some preliminary assessments. Next, the methodology used for the comparison is introduced. The analysis of the effect of the mechanism formulation on ozone concentrations is conducted by considering eight distinct species groups: non-carbonaceous inorganic species (nitrogen oxides and sulfur oxides), carbon monoxide, alkanes, anthropogenic alkenes, biogenic alkenes, aldehydes, alcohols and aromatic compounds. The analysis of differences in ozone concentrations is conducted for the whole domain and at specific locations including 8 urban sites and 4 remote areas. 
Among urban sites, some are $\mathrm{NO}_{x}$-sensitive for ozone formation and some are VOCsensitive. Three other sites are also included to characterize a high biogenic emissions region. The results are discussed in a diagnostic fashion to identify the causes of the discrepancies. Concluding remarks summarize the major differences between these two mechanisms.

\section{Model descriptions}

\subsection{Chemical kinetic mechanisms}

Condensed chemical mechanisms are mostly classified as lumped structure mechanisms and lumped species mechanisms. In a lumped structure mechanism, chemical organic compounds are divided into smaller species elements (functional groups) based on the types of carbon bonds in each species. In a lumped species mechanism, a particular organic compound or a surrogate species is used to represent several organic compounds of a same class (e.g., alkanes, alkenes and aromatics) which, for example, have similar reactivity with hydroxy radicals (Dodge 2000). We have chosen two mechanisms, one from each category, for this study. One is the lumped structure mechanism CB05 (Yarwood et al. 2005) and the other is the lumped species mechanism RACM2 (Goliff and Stockwell 2008, 2009). These two chemical mechanisms have been developed recently for regional scale applications. These mechanisms and their predecessors are widely used in AQMs. For example, CB05 and its previous versions are used in CMAQ (Community Multi-scale Air Quality), CAMx (the Comprehensive Air Quality Model with extensions), UAM-V (the Variable grid Urban Airshed Model), WRF/Chem (Weather Research and Forecasting model coupled with Chemistry). RACM2 and its previous versions (RACM and RADM2) are used for example in CMAQ, WRF/Chem, MM5/Chem (the Meteorological Mesoscale model, version 5 with Chemistry), EURAD (EURopean Air pollution Dispersion model) and POLAIR3D. General characteristics of the mechanisms are summarized in Table 1.

RACM2 is a new mechanism developed via various improvements made to RACM (Stockwell et al. 1997). Reaction rate constants were updated from different sources, e.g., NASA/JPL (Sander et al. 2006), IUPAC (Atkinson et al. 2006) and

Table 1 General characteristics of $\mathrm{CB} 05$ and RACM2

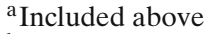

${ }^{\mathrm{b}}$ Including $\mathrm{XO}_{2}$ and $\mathrm{XO}_{2} \mathrm{~N}$

${ }^{c}$ Excluding $\mathrm{CO}_{2}, \mathrm{H}_{2}, \mathrm{H}_{2} \mathrm{O}, \mathrm{N}_{2}$ and $\mathrm{O}_{2}$
}

\begin{tabular}{lll}
\hline & CB05 & RACM2 \\
\hline Date of last major update & 2005 & 2008 \\
Total number of reactions & 156 & 349 \\
Number of inorganic reactions & 53 & 45 \\
Number of organic reactions $_{\text {Number of photolysis reactions }}^{\mathrm{a}}$ & 103 & 304 \\
Total number of species $_{\text {Number of stable inorganic species }}$ & 23 & 34 \\
Number of inorganic intermediates & $12^{\mathrm{b}}$ & $113^{\mathrm{b}}$ \\
Number of stable organic species & 29 & $12^{\mathrm{c}}$ \\
Number of organic intermediates & 7 & 56 \\
\hline
\end{tabular}


MCM 3.1 (Bloss et al. 2005). New developments in RACM2 include a new benzene scheme and new photolysis reactions for benzaldehyde and glyoxal. In the benzene scheme, phenol is explicitly speciated as a product of benzene oxidation (Goliff and Stockwell 2009). In RACM2, ozone destruction with oxygen atoms is included exclusively, though this reaction is important mostly near the tropopause. Furthermore, RACM2 treats reactions of oxygen atoms with molecular nitrogen and oxygen separately so that the altitude dependence due to different activation energies is considered (Stockwell 2009).

CB05 is an updated version of CBM-IV (Gery et al. 1989). In CB05, reaction rate constants were updated from the evaluations by IUPAC (Atkinson et al. 2005) and NASA/JPL (Sander et al. 2003). Additional inorganic reactions were included and 10 organic species were added to better represent stable organic species and radicals in the atmosphere (Luecken et al. 2008). CB05 has fewer species than RACM2, which makes it attractive for computational requirements; however, CB05 has more inorganic reactions than RACM2. Recent inorganic updates in CB05 include molecular hydrogen and oxygen atom reactions, more $\mathrm{NO}_{3}$ radical reactions, $\mathrm{N}_{2} \mathrm{O}_{5}$ photolysis and odd-oxygen and odd-hydrogen reactions, though most of these reactions are important only in the upper troposphere. In particular, $\mathrm{NO}_{3}$ radical reactions, the main driver for atmospheric chemistry at night, were added to improve nighttime chemistry (Yarwood et al. 2005). By this addition, $\mathrm{NO}_{3}$ destruction reactions in $\mathrm{CB} 05$ became similar to those in RACM2. Table 2 summarizes the inorganic reactions that differ between the two mechanisms.

To better represent aldehyde species, the two mechanisms include a new higher aldehyde species in common. These are ALDX in CB05 and ALD in RACM2, so that acetaldehyde (ALD2 in CB05, ACD in RACM2) chemistry is explicitly represented. It was treated with other higher aldehydes previously in CBM-IV and RACM. In CB05, a new species TERP was added to represent monoterpenes; in RACM2, monoterpenes are represented by two surrogate species API and LIM (Yarwood et al. 2005; Goliff and Stockwell 2009).

Table 2 Different inorganic reactions in CB05 and RACM2

\begin{tabular}{|c|c|c|c|}
\hline Type & Reaction $^{\mathrm{a}}$ & $\begin{array}{l}\text { Reaction no. } \\
\text { in CB05 }\end{array}$ & $\begin{array}{l}\text { Reaction no. } \\
\text { in RACM2 }\end{array}$ \\
\hline Molecular hydrogen reaction & $\mathrm{O} 1 \mathrm{D}+\mathrm{H}_{2} \rightarrow \mathrm{OH}+\mathrm{HO}_{2}$ & R38 & $\mathrm{X}$ \\
\hline \multirow[t]{2}{*}{$\mathrm{NO}_{3}$ radical reactions } & $\mathrm{NO}_{3}+\mathrm{O}_{3} \mathrm{P} \rightarrow \mathrm{NO}_{2}$ & R46 & $\mathrm{X}$ \\
\hline & $\mathrm{NO}_{3}+\mathrm{O}_{3} \rightarrow \mathrm{NO} 2$ & R49 & $\mathrm{X}$ \\
\hline $\mathrm{NO}_{x}$ recycling reaction & $\mathrm{N}_{2} \mathrm{O} 5 \rightarrow \mathrm{NO}_{2}+\mathrm{NO}_{3}$ photolysis & R53 & $\mathrm{X}$ \\
\hline Odd-oxygen and & $\mathrm{OH}+\mathrm{O}_{3} \mathrm{P} \rightarrow \mathrm{HO}_{2}$ & R40 & $\mathrm{X}$ \\
\hline \multirow[t]{7}{*}{ odd-hydrogen reactions } & $\mathrm{OH}+\mathrm{OH} \rightarrow \mathrm{O}_{3} \mathrm{P}$ & R41 & $\mathrm{X}$ \\
\hline & $\mathrm{OH}+\mathrm{OH} \rightarrow \mathrm{H}_{2} \mathrm{O}_{2}$ & R42 & $\mathrm{X}$ \\
\hline & $\mathrm{HO}_{2}+\mathrm{O}_{3} \mathrm{P} \rightarrow \mathrm{OH}$ & R44 & $\mathrm{X}$ \\
\hline & $\mathrm{H}_{2} \mathrm{O}_{2}+\mathrm{O}_{3} \mathrm{P} \rightarrow \mathrm{OH}+\mathrm{HO}_{2}$ & R45 & $\mathrm{X}$ \\
\hline & $\mathrm{O}_{3} \mathrm{P}+\mathrm{O}_{3} \rightarrow 2 \mathrm{O}_{2}$ & $\mathrm{X}$ & R36 \\
\hline & $\mathrm{O}_{1} \mathrm{D}+\mathrm{N}_{2} / \mathrm{O}_{2} \rightarrow \mathrm{O}_{3} \mathrm{P}$ & $\mathrm{X}$ & R37, R38 \\
\hline & $\mathrm{O}_{1} \mathrm{D}+\mathrm{M} \rightarrow \mathrm{O}_{3} \mathrm{P}$ & $\mathrm{R} 10$ & $\mathrm{X}$ \\
\hline
\end{tabular}

$X$ means that the reaction is not treated in the mechanisms

${ }^{a}$ Written with model species notation 
2.2 The Polyphemus air quality modeling system

Polyphemus version 1.3.1 and its AQM Polair3D were used for this study (http:// cerea.enpc.fr/polyphemus/index.html). To generate chemistry modules that allow using new chemical mechanisms in the Polyphemus platform, we applied an automatic preprocessor, SPACK (Simplified Preprocessor for Atmospheric Chemical Kinetics). This preprocessor converts a symbolic notation of chemical reactions to a mathematical set of ordinary differential equations and a large numbers of chemical equations can easily be treated (Djouad et al. 2002). A detailed description of Polyphemus is provided by Mallet et al. (2007).

\subsection{Modeling domain, episode and setup}

The modeling domain is identical to the one in Sartelet et al. (2007) and covers western and part of eastern Europe. The coordinates of the southwestern point are $\left(10.75^{\circ} \mathrm{W}, 34.75^{\circ} \mathrm{N}\right)$ in longitude/latitude. The domain of simulation covers an area of $33.5^{\circ} \times 23^{\circ}$ with a step of $0.5^{\circ}$ along both longitude and latitude. Five vertical levels are considered from the ground to $3000 \mathrm{~m}$. The heights of the cell interfaces are 0 , $50,600,1200,2000$ and $3000 \mathrm{~m}$. The simulations were carried out for one month from 15 July to 15 August 2001, with a two-week spin-up period. The aim of the spin-up period is to get realistic initial conditions. Because of the greater number of species treated in RACM2, a model simulation took about twice more computational time with RACM2 than with CB05.

Photolysis rates were computed off-line by the photolysis preprocessor Fast-J, which calculates photolysis rates in the presence of an arbitrary mix of cloud and aerosol layers (Wild et al. 2000). The dry deposition velocities were preprocessed using the parameterization scheme for the gaseous dry deposition in AURAMS (Zhang et al. 2002). Meteorological inputs were obtained from reanalysis provided by the European Centre for Medium-Range Weather Forecasts (ECMWF), and vertical diffusion was computed using the Troen-Mahrt (1986) parameterization and the Louis (1979) parameterization.

Anthropogenic emissions were generated with the European Monitoring and Evaluation Programme (EMEP) inventory for 2001. The inventory is provided as total non-methane hydrocarbon (NMHC) and was subsequently disaggregated into molecular volatile organic compound (VOC) species using Passant's speciation coefficients (Passant 2002). Model species emissions were derived from the molecular species, according to speciation rules available for each mechanism (Yarwood et al. 2005; Goliff and Stockwell 2009). Although the mechanism developers' own databases are also available, Carter's speciation database (Carter 2008) was used here for the two mechanisms to maintain consistency for emission speciation. In any case, differences between Carter's speciation database and the mechanism developers' databases appear to be minor. Biogenic emissions were computed as in Simpson et al. (1999). Two-thirds of monoterpene emissions were allocated to $\alpha$-pinene and one-third to limonene in RACM2 (Johnson et al. 2006), whereas all monoterpenes were simply allocated to model species TERP in CB05. 


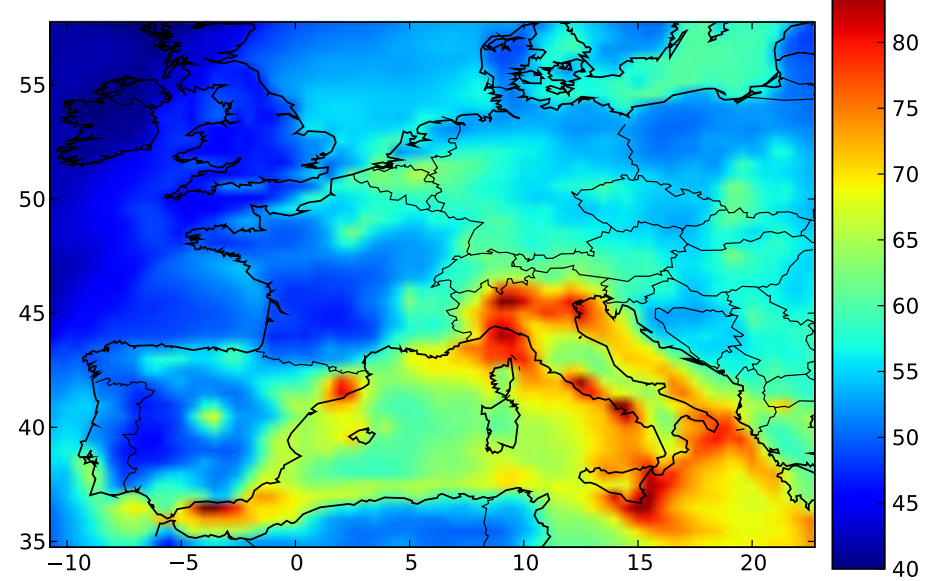

(a)

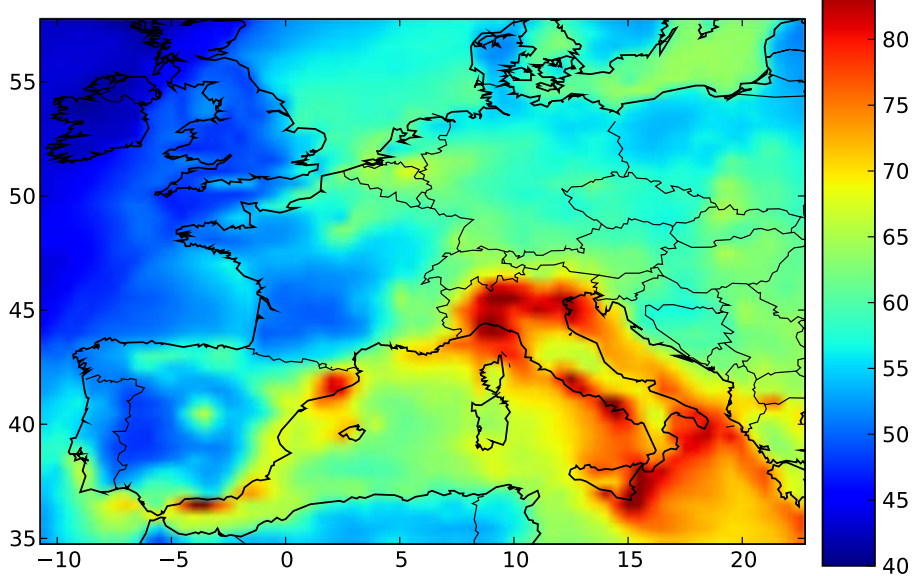

(b)

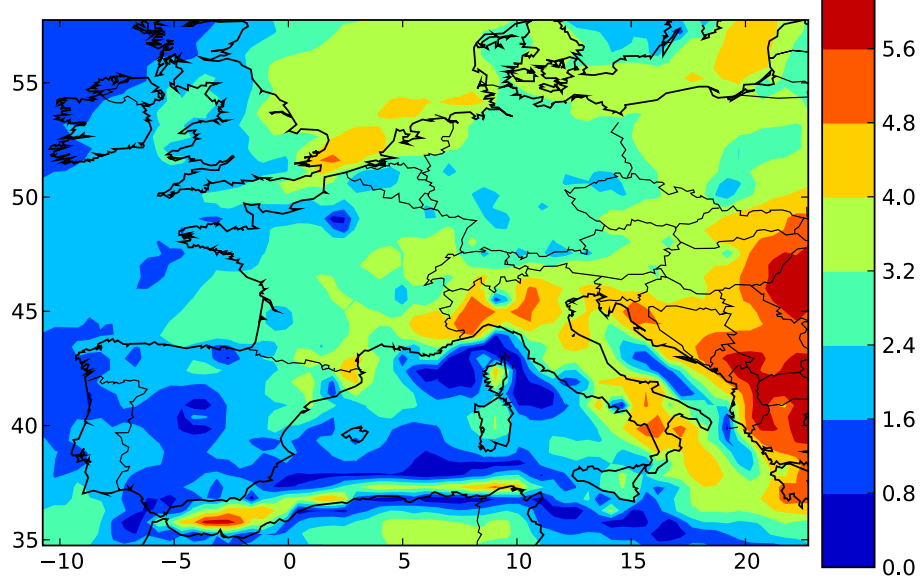

(c) 


\subsection{Preliminary assessments}

Model performance was evaluated using the EMEP ozone concentration data available hourly at 92 stations. The mean normalized error and bias (using a 30 ppb threshold) were $23 \%$ and $9 \%$, respectively, for RACM 2 and $21 \%$ and $4 \%$, respectively, for CB05. These results compare favorably with performance standards, typically $\leqslant$ $35 \%$ for error and $\leqslant 15 \%$ for bias (Russell and Dennis 2000). Root-mean square errors are 17 and $16 \mathrm{ppb}$ and correlations of hourly ozone concentrations are 0.56 and 0.55 for RACM2 and CB05, respectively. Such results are commensurate with earlier model performance results for Europe (e.g., van Loon et al. 2007; Sartelet et al. 2007; Honoré et al. 2008).

Monthly averages of daily maximum $8 \mathrm{~h}$-average ozone concentrations ( $8 \mathrm{~h}$ maximum below) are not significantly different between the two chemical mechanisms. Using mean fractional absolute difference defined by

$$
\frac{1}{n} \sum_{i=1}^{n} \frac{\left|\left[O_{3}\right]_{C B 05}-\left[O_{3}\right]_{R A C M 2}\right|}{\left(\left[O_{3}\right]_{C B 05}+\left[O_{3}\right]_{R A C M 2}\right) / 2}
$$

the difference between $\mathrm{CB} 05$ and RACM2 is $5 \%$ over the entire domain and the mean value of those $\mathrm{O}_{3}$ concentrations in CB05 is lower than that in RACM2 by $2.6 \mathrm{ppb}$. The maximum local differences between the two mechanisms are $6.1 \mathrm{ppb}$ $(9 \%)$ for locations where $\mathrm{O}_{3}$ concentrations predicted by RACM2 are greater and $5.9 \mathrm{ppb}(9 \%)$ for locations where $\mathrm{O}_{3}$ concentrations predicted by $\mathrm{CB} 05$ are greater. Figure 1 presents the modeled ozone concentrations over the entire domain for the two mechanisms and monthly average of the corresponding differences by modulus. Differences are large (> $4 \mathrm{ppb}$ ) along the coastline of northern Africa (9\%) and in eastern Europe (9\%). The difference along the coastline of northern Africa disappears when the biogenic VOC emissions are not included (not shown here). Ozone formation in that area results mostly from the interaction of biogenic emissions from land with $\mathrm{NO}_{x}$ emissions from marine traffic along the North African coast. Therefore, the difference in ozone concentration results from different treatments of the biogenic VOC chemistry and $\mathrm{NO}_{x}$ kinetics between the two mechanisms. Smaller differences are obtained in some large cities (about 3\% in Paris, Madrid, Rome, Milan and Barcelona) and in some marine region $(2.5 \%$ in the Ligurian Sea and the Adriatic Sea) but those differences stand out against the regional background as shown in Fig. 1c. The ozone concentration in the Italian Peninsula is the highest in Europe for both CB05 and RACM2. The two mechanisms predict ozone concentrations above the current European ozone target value $\left(120 \mu \mathrm{g} / \mathrm{m}^{3}\right.$ for 8h-maximum by EU Directive 2008/50/CE) there, as well as in the Strait of Gibraltar, Barcelona, Paris and Madrid. Because RACM2 overall predicts slightly more ozone than $\mathrm{CB} 05, \mathrm{O}_{3}$ concentrations in some parts of the domain can exceed the European target value with RACM2 while they do not with CB05.

Significant differences of the ozone concentration between the two mechanisms are observed in remote areas far from urban regions. In Fig. 1c, these differences

Fig. 1 Monthly average of daily maximum 8h-average ozone concentrations (ppb) modeled with a CB05 and b RACM2, and differences between the two model simulations by modulus c CB05 RACM2 
appear clearly in eastern Europe, the coastline of northern Africa, Italian Peninsula, North Sea and Ionian Sea. Smaller differences are observed in other parts of the Mediterranean Sea and western Europe except Italy. Remote regions can be classified by their ozone characteristics in four categories.

1. High ozone concentration and high ozone difference (Italian Peninsula and Ionian Sea)

2. High ozone concentration and low ozone difference (Ligurian Sea and Sicily)

3. Low ozone concentration and high ozone difference (the coastline of northern Africa and North Sea)

4. Low ozone concentration and low ozone difference (most of western Europe)

Similar discrepancies in remote areas were observed in a comparison between CB05 and CBM-IV mechanisms (Luecken et al. 2008). These differences for the remote areas are discussed in detail in Section 4.2.

\section{Comparison methodology}

\subsection{Categorization of volatile organic compounds}

Our objective is to compare the two mechanisms in a systematic fashion in order to identify the causes of the most significant differences in ozone formation. To that end, we compare the two mechanisms first for the effect on $\mathrm{O}_{3}$ of inorganic chemistry only. Next, we investigate the effect of organic chemistry on ozone formation. Since it is well established (e.g., Bowman et al. 1995; Carter et al. 1995; Carter 1995; Martien et al. 2003; Hakami et al. 2004; Derwent et al. 2007) that different classes of volatile organic compounds (VOC) have different reactivities with respect to ozone formation, it seems appropriate to investigate the treatment of ozone formation in both mechanisms by VOC classes. One possibility is to study how each model species (i.e., the carbon-bond species in CB05 and the surrogate molecules in RACM2) leads to ozone formation. Such an approach, however, does not lend itself to a straightforward comparison because there is no direct correspondence between the model species of the two mechanisms except for a few cases (e.g., formaldehyde and acetaldehyde). Another possibility is to study how each mechanism treats ozone formation for a class of VOC defined before processing into model species. This second approach offers the advantage of being consistent with experimental and theoretical investigations conducted on VOC reactivity. It also takes into account the processing of actual VOC classes into model species, which is a major component of a condensed chemical kinetic mechanism. Therefore, this second approach was selected here for our comparison of CB05 and RACM2.

Two distinct methods can be used to investigate the influence of $\mathrm{CO}$ or a VOC class on ozone formation: (1) CO or a VOC class can be removed from the simulation (i.e., its emissions, boundary conditions and initial conditions) and its effect can then be estimated by comparing the base simulation (with all species) and the sensitivity simulation (with all species except CO or the VOC class); (2) CO or the VOC class can be added to a simulation containing only inorganic species except $\mathrm{CO}$ (i.e., nitrogen and sulfur species, $\mathrm{NO}_{y}$ and $\mathrm{SO}_{x}$ ) and its effect can be estimated by comparing the simulation with only $\mathrm{NO}_{y}$ and $\mathrm{SO}_{x}$ species and a simulation with these 
species plus $\mathrm{CO}$ or the VOC class studied. The first method analyzes the differences between the two mechanisms in a context similar to that used to define incremental reactivity, i.e., the contribution of $\mathrm{CO}$ or a VOC class to ozone formation is estimated in the presence of nitrogen oxides $\left(\mathrm{NO}_{x}\right)$ and other carbonaceous compounds. The second method focused on the differences between the two mechanisms when only the chemistry of $\mathrm{CO}$ or a VOC class takes place in the presence of $\mathrm{NO}_{x}$. Because the relationship between ozone formation and carbonaceous emissions is highly nonlinear, the two methods will give different results. Consequently, we applied both methods in this study (note that for a class such as aldehydes, removing emissions and other inputs does not lead to a complete removal of that class because aldehydes are produced during the oxidation of other classes of VOC).

CB05 and RACM2 have predefined speciation rules to convert molecular VOC species to model species. For example, the paraffinic carbon model species PAR in CB05 appears in all types of anthropogenic VOC emissions species : alkanes, alkenes, aldehydes, alcohols and aromatic compounds. In RACM2, the model species HC5, for example, is used for both alkanes and some alcohols (those with more than two carbons). Figure 2 shows some examples of such distributions of model species among the different VOC classes for the two mechanisms. When defining VOC classes, an issue arises for benzaldehyde, which consists of a benzene ring with an aldehyde substituent; we chose to include it in both aldehyde and aromatic compound categories.

For the first method, the reference simulation uses all emissions (hereafter AllEmis). The sensitivity simulations use the full emission inventory, but the emissions, boundary conditions and initial conditions of a carbonaceous category are removed: $\mathrm{CO}$, aldehydes, alkanes, biogenic alkenes, aromatic compounds, anthropogenic alkenes, alcohols (these simulations are referred to hereafter as NoCO, NoAldehy, NoAlkane,NoBioAlkene, NoAromat, NoAnthAlkene and NoAlcohol, respectively). Similarly, for the second method, the reference simulation is referred to as NOySOx and emissions, boundary conditions and initial conditions of $\mathrm{CO}$ and each VOC class were added separately to the reference simulation, NOySOx in 7 distinct sets of simulations (these simulations are hereafter referred to as WithCO,

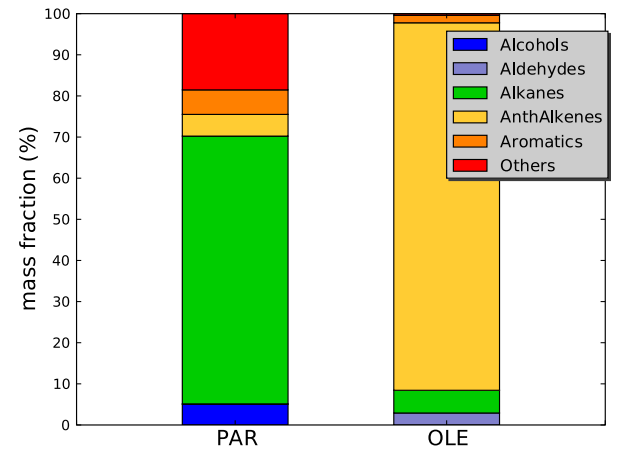

(a) $\mathrm{CB} 05$

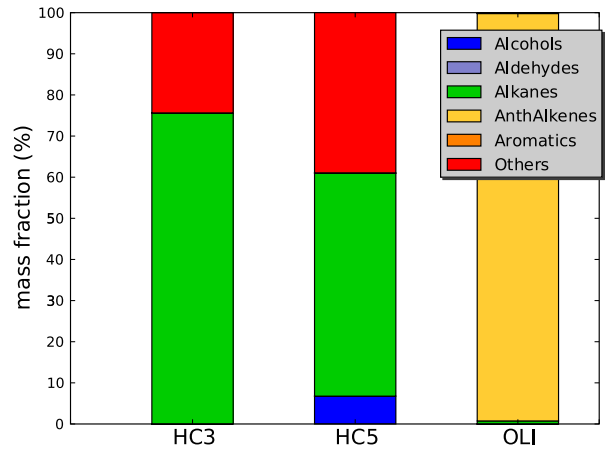

(b) RACM2

Fig. 2 Examples of distribution of some model species among VOC categories for the European emission inventory 
WithAldehy, WithAlkane, WithBioAlkene, WithAromat, WithAnthAlkene and WithAlcohol, respectively).

\subsection{Indicators for $\mathrm{NO}_{x}$-VOC sensitivity}

The ozone-precursor relationship can be understood in terms of $\mathrm{NO}_{x}$-sensitive and VOC-sensitive (or $\mathrm{NO}_{x}$-saturated) chemical regimes (Sillman 1999) and it is useful to understand these chemical regimes in the modeling domain when analyzing differences between the mechanisms. To predict $\mathrm{NO}_{x}$-VOC sensitivity for each location, one may compare differences between $\mathrm{O}_{3}$ concentrations in a base model simulation and those in simulations with, for example, $35 \%$ reductions in anthropogenic VOC and in $\mathrm{NO}_{x}$. Because the estimations of $\mathrm{NO}_{x}$ - and VOC-sensitivity at individual locations are often very uncertain (Sillman 1999), two distinct methods were used here.

First, as done in Sillman and He (2002), locations are classified according to the following definitions:

1. $\mathrm{NO}_{x}$-sensitive: $\mathrm{O}_{3}$ in the scenario with reduced $\mathrm{NO}_{x}$ (Reduc- $\mathrm{NO}_{x}$ below) is lower than $\mathrm{O}_{3}$ in both the base case (Base below) and in the scenario with reduced VOC (Reduc-VOC below) at the specified location by at least a few ppb (which is referred to as the threshold in the following).

2. VOC-sensitive: $\mathrm{O}_{3}$ in the Reduc-VOC is lower than $\mathrm{O}_{3}$ in both the Base and the Reduc- $\mathrm{NO}_{x}$ by at least the threshold.

3. Mixed: Both the Reduc-NO $\mathrm{N}_{x}$ and the Reduc-VOC have $\mathrm{O}_{3}$ lower than in the Base by at least the threshold, and their reciprocal difference is within the threshold.

4. $\mathrm{NO}_{x}$-titration: $\mathrm{O}_{3}$ in the Reduc- $\mathrm{NO}_{x}$ is larger than $\mathrm{O}_{3}$ in the Base by at least the threshold, and difference between $\mathrm{O}_{3}$ in the Reduc-VOC and $\mathrm{O}_{3}$ in the Base is within the threshold.

All other locations are viewed as insensitive to $\mathrm{NO}_{x}$ and $\mathrm{VOC}$ in the context of the model domain. In this study, a monthly-averaged $\mathrm{O}_{3}$ concentration was used at each location to estimate the overall chemical regime (this is an approximation because VOC- or $\mathrm{NO}_{x}$-sensitivity may vary over time; it is nevertheless appropriate for our purpose here).

The second method is simpler than the first but also appropriate. The difference of the averaged ozone concentration between the Reduc-NO $\mathrm{N}_{x}$ and the Reduc-VOC is estimated at each location. The positive value of the difference is regarded as VOCsensitive chemistry and the negative value is regarded as $\mathrm{NO}_{x}$-sensitive chemistry (Junier et al. 2005; Sportisse 2008). Figure 3 displays the results of the two methods for $\mathrm{NO}_{x}$-VOC sensitivity over the modeling domain.

The two methods give similar results about the locations that are $\mathrm{NO}_{x}$-sensitive or VOC-sensitive for ozone formation. As expected, the VOC-sensitive regime appears mostly in polluted urban regions in northwestern Europe whereas the $\mathrm{NO}_{x}$-sensitive regime dominates the southern parts of Europe where biogenic alkenes emissions are abundant (Curci et al. 2009). These results agree well with some previous studies. For example, Kuebler et al. (1996) showed that ozone production was limited by $\mathrm{NO}_{x}$ in Switzerland whereas Dommen et al. (2002) reported VOC-sensitive chemistry in Milan. Ozone formation in the Paris region has been estimated to be either VOC- 


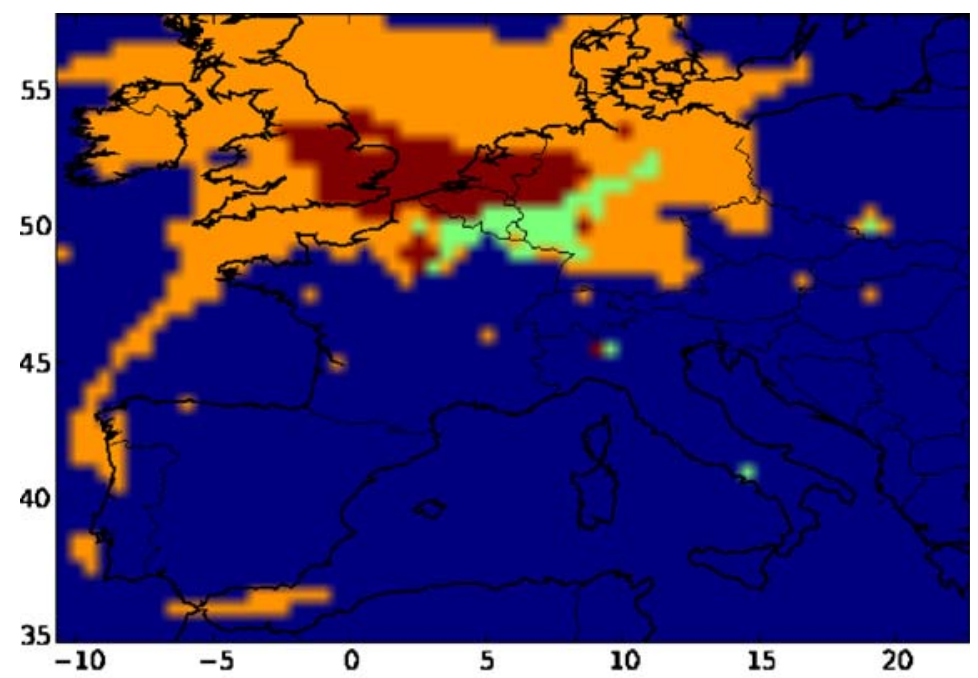

(a) Method of Sillman and He (2002) - Red: VOC-sensitive; Blue: NO $x$-sensitive; Green: Mixed; Orange: insensitive, when the threshold is $2 \mathrm{ppb}$

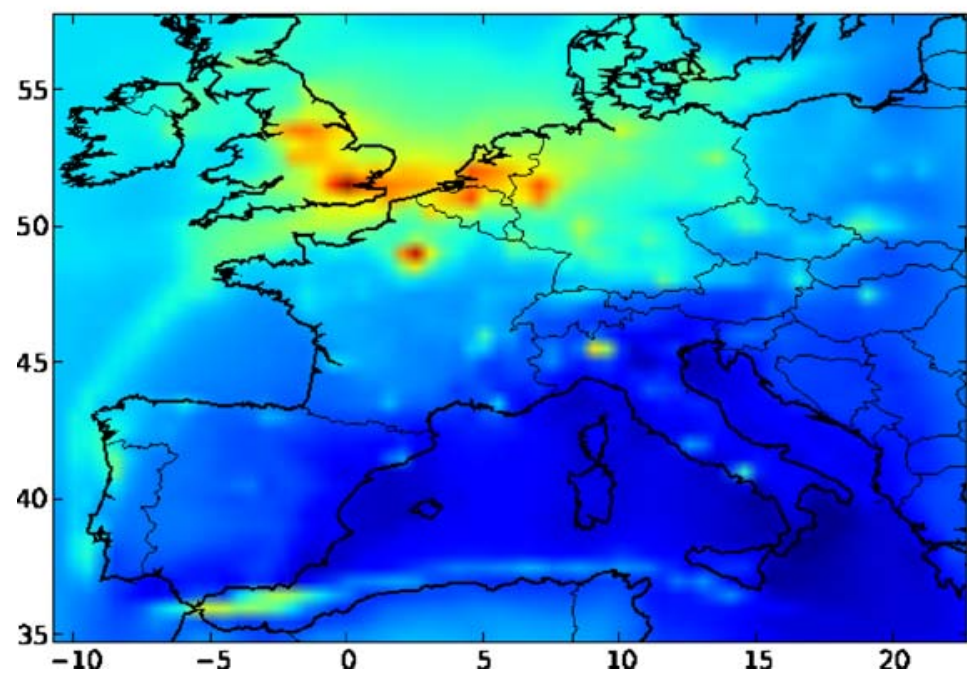

(b) Method of Junier et al. (2005) - Red and yellow: VOC-sensitive; Blue : $\mathrm{NO}_{x^{-}}$ sensitive; Green: mixed or insensitive

Fig. $3 \mathrm{NO}_{x}$-VOC sensitivity distributions over Europe in this study (15 July-15 August 2001 simulation)

or $\mathrm{NO}_{x}$-sensitive (Honoré et al. 2000; Menut et al. 2000; Sillman et al. 2003); it is classified here as VOC-sensitive on average for Paris and with mixed sensitivity for Fontainebleau, where $\mathrm{NO}_{x}$-sensitive would be expected but a $\mathrm{NO}_{x}$ plume from Paris can have an effect on the chemical regime (Tulet et al. 2000).

The chemical regime in a location is determined by the concurrence of $\mathrm{NO}_{x}$ and VOCs emission rates and regional transport. In Fig. 4, it appears that high $\mathrm{NO}_{x}$ 


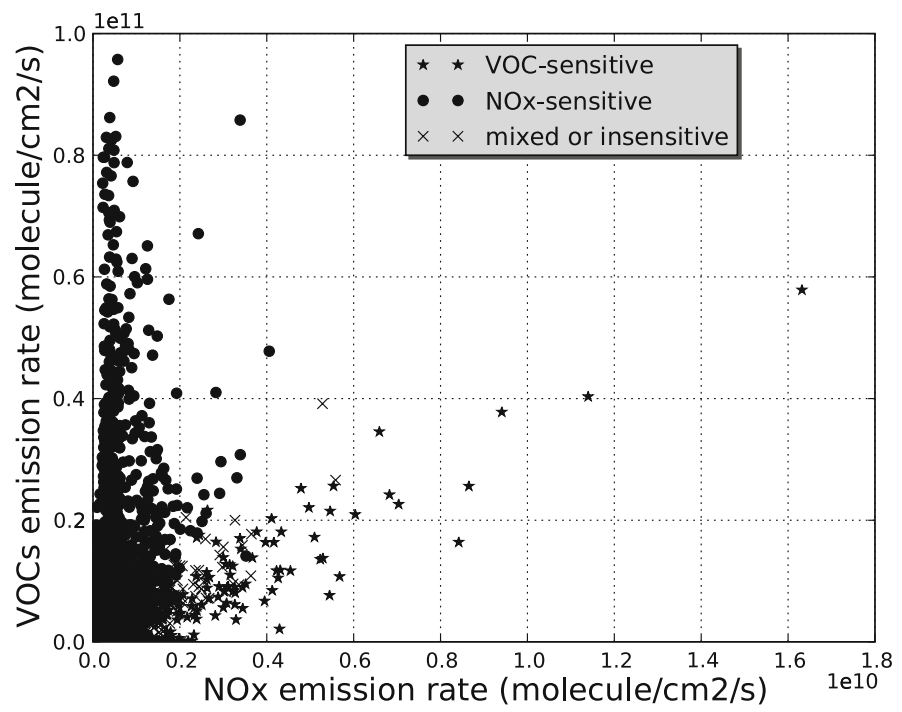

Fig. 4 Sensitivity in each location determined by emission rates of ozone precursors. The emission rates are averaged values during the whole simulation period (July 15 to August 15). Each point represents a grid cell of the simulation domain; star, circle and cross correspond to the chemical regimes, defined in each grid cell as VOC-sensitive, $\mathrm{NO}_{x}$-sensitive and mixed or insensitive, respectively (see text)

emission rate in a given location leads to VOC-sensitive (star) chemical regime in that point and high VOCs emission rate causes $\mathrm{NO}_{x}$-sensitive (circle) regime there. The results from the second sensitivity estimation method above were used to display the sensitivity in each location.

\subsection{Selection of sites for analysis}

Because ozone is both an urban and a regional pollutant, it is desirable to study its chemistry at both urban and non-urban receptors (e.g., Zhang et al. 2005, Luecken et al. 2008). Therefore, to highlight differences between the two mechanisms for $\mathrm{O}_{3}$ formation at different locations and under different chemical regimes, we chose several locations (grid cells) including 8 cities and 4 remote areas. Based on the results of the $\mathrm{NO}_{x}$-VOC sensitivity (see Fig. 3), four urban locations were selected respectively in the $\mathrm{NO}_{x}$-sensitive region and the $\mathrm{VOC}$-sensitive region to investigate the influences related to the chemical regimes in addition to differences in emission levels. The four non-urban sites were taken to represent different ozone levels and discrepancies between the chemical mechanisms. For two non-urban sites, low ozone concentrations are simulated with the two mechanisms but the difference of the $\mathrm{O}_{3}$ concentrations at one site was higher than that at the other. Similarly, at the two other non-urban sites where high ozone concentrations are simulated, the differences in ozone formation by the two mechanisms differed.

In Europe during this 2001 summer simulation, high biogenic emissions occur mostly in the Iberian Peninsula (Simpson et al. 1999). Accordingly, three receptors were selected as representatives of the biogenic emission region to focus on the 


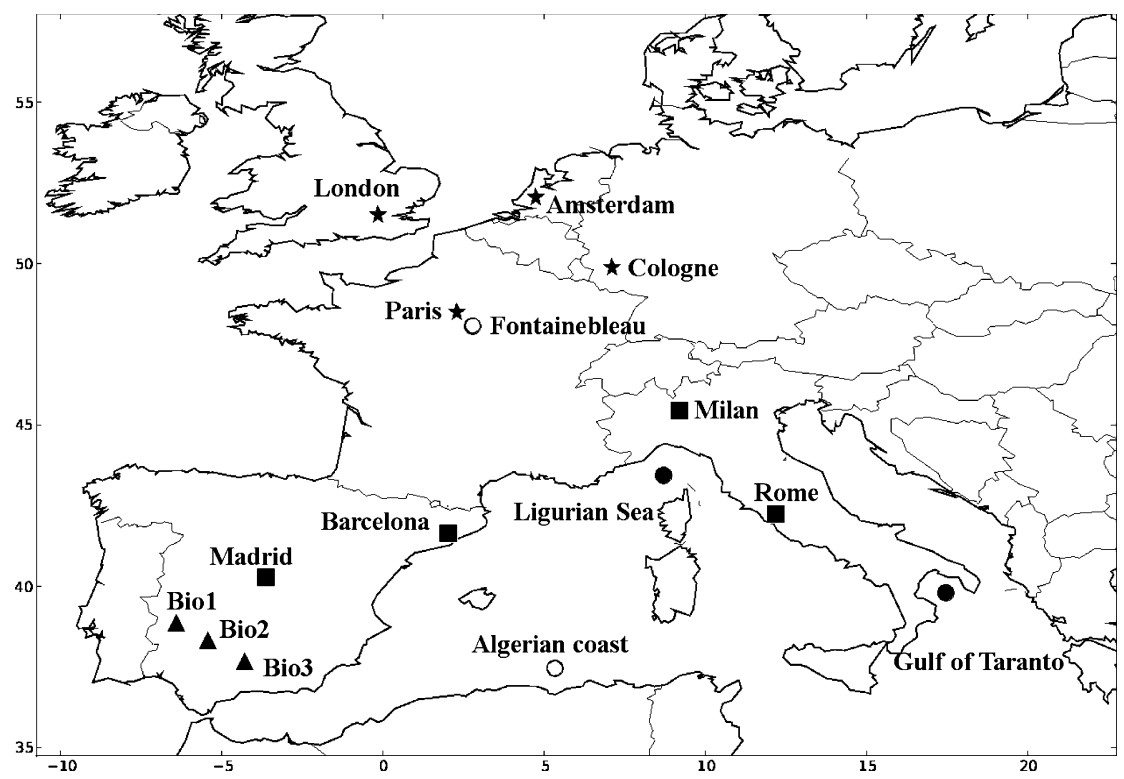

Fig. 5 Locations of model grid cells used in the analysis. Stars and squares indicate $\mathrm{NO}_{x}$-sensitive and VOC-sensitive urban areas, respectively; circles indicate non-urban areas (white circle: low ozone $(<65 \mathrm{ppb})$, black circle: high ozone (> $75 \mathrm{ppb})$ and triangles indicate locations with strong biogenic emissions

characteristics of $\mathrm{CB} 05$ and RACM2 in the region where biogenic alkenes are abundantly emitted. Figure 5 illustrates the sites selected.

\section{Results}

\subsection{Ozone spatial distributions}

Difference in ozone concentrations obtained between the two mechanisms is studied by investigating the relative contribution of inorganic versus organic chemistry. The major differences in the inorganic chemistry are the kinetics of $\mathrm{NO}$ oxidation by $\mathrm{O}_{3}$ and $\mathrm{HO}_{2}$. The kinetics of the first one is greater in CB05 than in RACM2, whereas the kinetics of the second one is greater in RACM2 than in CB05 (both by about $10 \%$ at $298 \mathrm{~K}$ ). Consequently, inorganic chemistry is more conducive to $\mathrm{O}_{3}$ formation in RACM2 than in CB05.

If one uses the RACM2 kinetics of these reactions in CB05, the mean fractional absolute difference in average ozone concentration over the whole domain is $5 \%$ between the two versions of CB05. It is 3\% between CB05 and RACM2 when the same NO kinetics is used, with CB05 producing more ozone. Therefore, inorganic chemistry leads to a difference between the two mechanisms as significant as that due to organic chemistry. As discussed below, there are some compensating effects in the differences due to organic chemistry. Nevertheless, this result highlights the fact that both inorganic and organic chemistry contribute to differences between mechanisms. 


\subsubsection{Sensitivity methods}

Following Section 3.1, two methods are used to investigate the influence of CO or a VOC class on ozone formation. In method 1, the reference simulation includes all species (their emissions, boundary conditions and initial conditions); in method 2, it includes only inorganic species. For each method, Fig. 6 displays the differences between each emission sensitivity case and the corresponding reference case of the monthly average of daily $8 \mathrm{~h}$-maximum ozone concentrations averaged over the entire domain. Results are shown for CB05 and RACM2; the differences between the results obtained with the two mechanisms are also shown. The largest differences ( $\sim 1$ to $5 \mathrm{ppb}$ ) between the two mechanisms are obtained with both methods for carbon monoxide, aromatic compounds and biogenic alkenes (NoCO, NoAromat, WithCO, WithAromat and WithBioAlkene). In the case of the NoCO and NoAromat scenarios, CB05 predicts more ozone at the coastline of northern Africa, the Ligurian Sea, Paris and Madrid, but RACM2 predicts higher ozone concentrations in southern France, Switzerland, Italy and eastern Europe. RACM2 predicts greater ozone concentrations than CB05 over the whole domain in the WithCO and WithAromat cases. In the WithAromat case, the largest differences are obtained in northern Italy and Barcelona; in the WithCO case, they are obtained in northern Italy and the Baltic Sea. In the case of the WithBioAlkene, CB05 predicts greater ozone concentrations than RACM2 over the whole domain (see Fig. 7). Overall, RACM2 has more reactive CO and aromatic VOC chemistry than CB05. On the other hand, the latter oxidizes alkane compounds and biogenic alkenes more effectively than the former. Results are mixed depending on the method for the other VOC classes. The reasons for these differences are discussed in Section 4.2.

\subsubsection{Emission rates consideration}

The analysis presented above addressed the effect of the chemical mechanism given the European emission inventory. Therefore, a VOC class with a large emission rate is more likely to lead to a significant difference between the two mechanisms than a VOC class with a small emission rate, everything else being equal. The differences discussed above are of interest because they are directly relevant to the results of an air quality simulation. However, it is also of interest to investigate whether the chemistry of a VOC class may differ significantly between the two mechanisms, even if the impact for the air quality simulation remains small because that VOC class has small emissions relative to other categories. To that end, we repeated the analysis presented above by normalizing the differences in ozone concentrations by the emission rate of the corresponding VOC class or CO. Thus, we define the normalized ozone differences in each emission sensitivity case as follows

$$
\frac{\left[\mathrm{O}_{3}\right]_{\text {case }}-\left[\mathrm{O}_{3}\right]_{\text {ref }}}{\text { MoleC }_{\text {case }} / \mathrm{MoleC}_{\text {total }}}
$$

where $M o l e C_{\text {case }}$ and $M o l e C_{\text {total }}$ are the total emissions (in moles of $\mathrm{C}$ ) for the emission scenario case and the reference case, respectively.

Figure 8 presents those normalized ozone differences for the two mechanisms and their differences. From this analysis, significant differences appear between CB05 and RACM2 for aldehydes, anthropogenic alkenes, aromatics and alkanes. Aldehydes show significant differences with both methods. The difference in the 


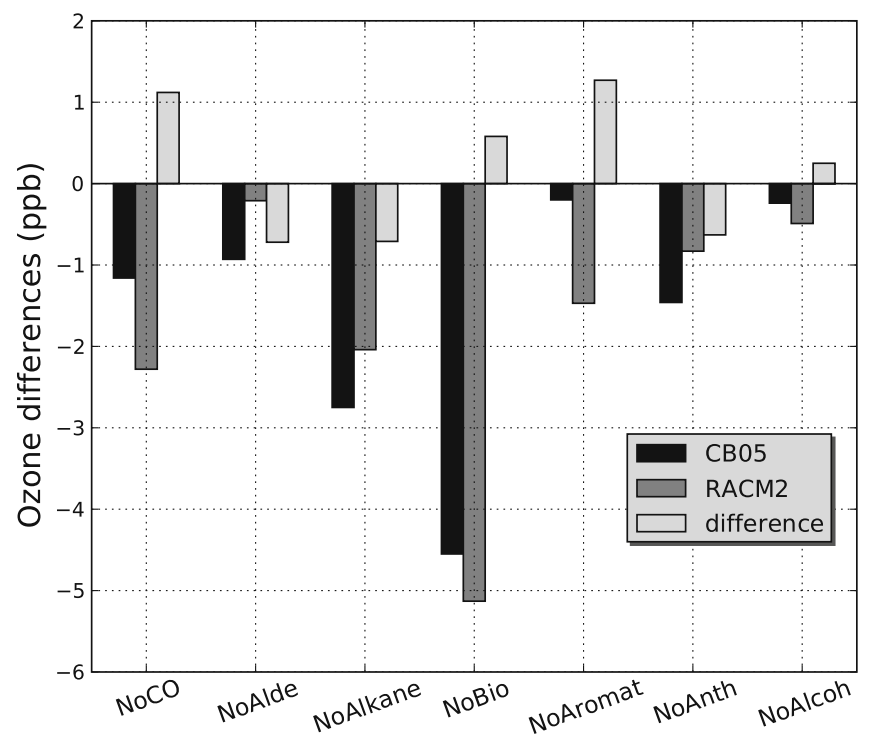

(a) Method 1

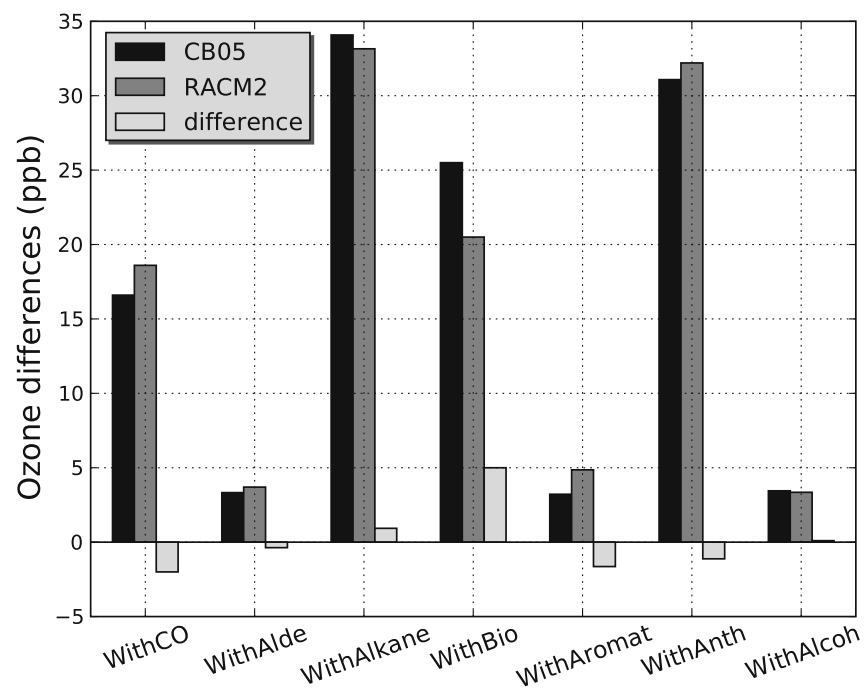

(b) Method 2

Fig. 6 Differences of the monthly averaged daily maximum 8-h average ozone concentrations averaged over the entire domain (ppb) between the emission scenario case and the reference case and differences between CB05 and RACM2 results. The reference case is AllEmis for the first method and NOySOx for the second method

NoAldehy case is significant as CB05 predicts an effect that is 3.5 times greater than that of RACM2. This effect was limited in Fig. 6 because the aldehyde class has a small emission rate $(0.3 \%$ of total carbon atoms). The differences, which occur in the NoAldehy and WithAldehy cases are significant (2.4 ppb and $1.2 \mathrm{ppb}$ for 

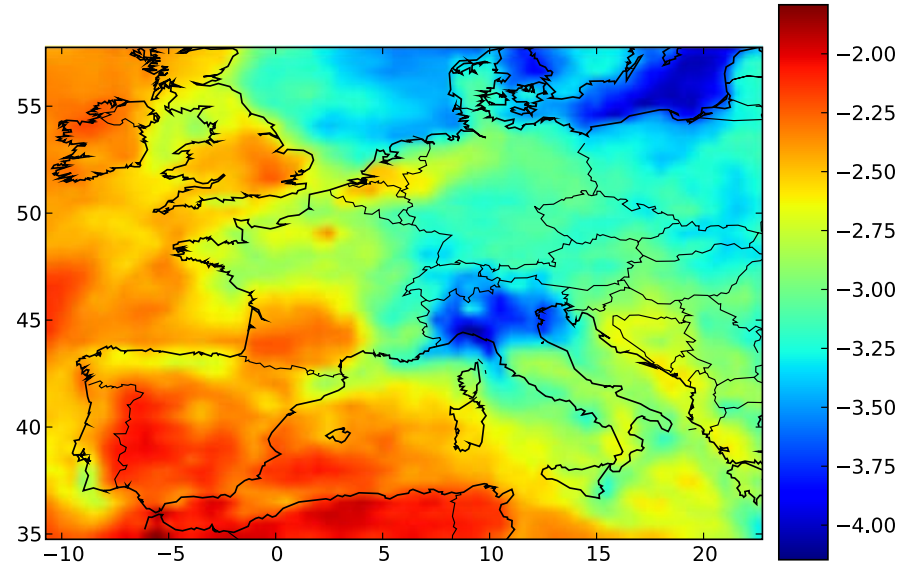

(a) WithCO case

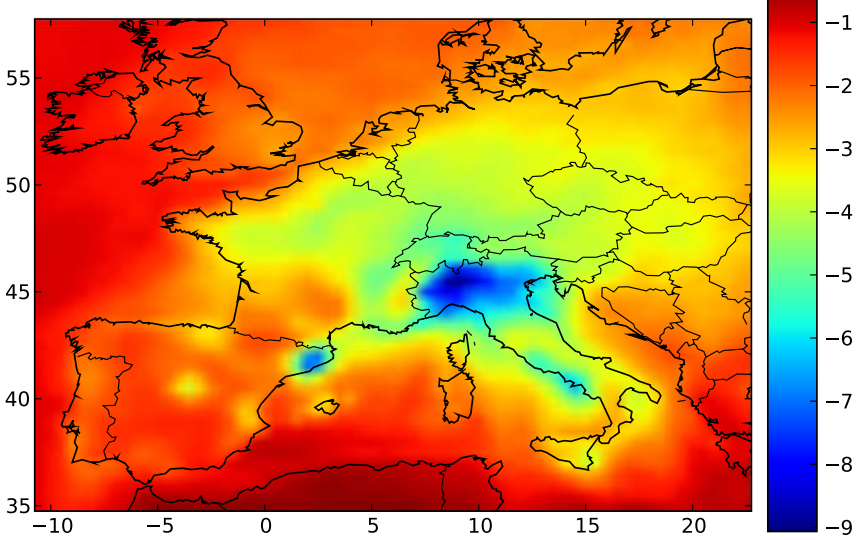

(b) WithAromat case

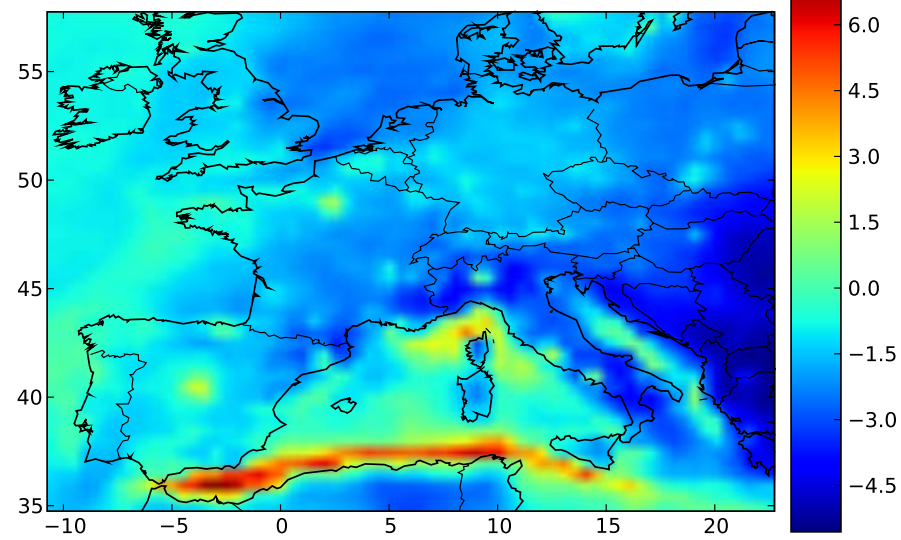

(c) $\mathrm{NoCO}$ case

Fig. 7 Differences in monthly-averaged daily maximum 8-h average ozone concentration (ppb) between $\mathrm{CB} 05$ and RACM2 for five emission scenario cases: a CO, method 2; $\mathbf{b}$ aromatics, method $2 ; \mathbf{c ~ C O}$, method $1 ; \mathbf{d}$ aromatics, method $1 ; \mathbf{e}$ biogenic alkenes, method 2 


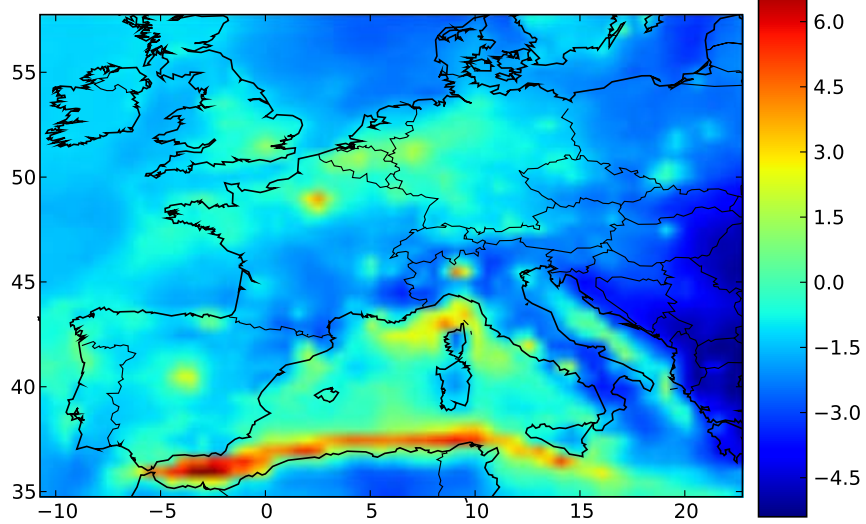

(d) NoAromat case

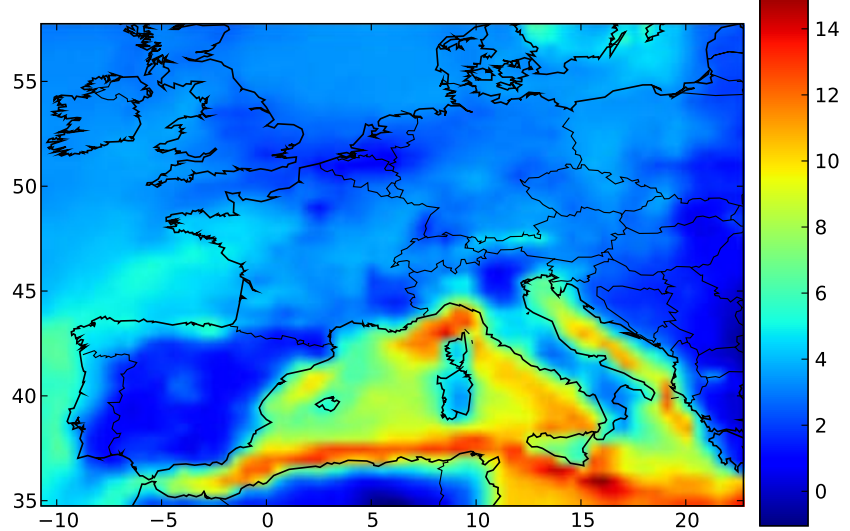

(e) WithBioAlkene case

Fig. 7 (continued)

$\left[\mathrm{O}_{3}\right]$, respectively), but the difference is more evident when the overall influence of aldehyde chemistry is maximized by the presence of other VOC classes.

\subsection{Local ozone distributions}

\subsection{1 $\mathrm{NO}_{x}$ - and $V O C$-sensitive regimes in urban areas}

We discuss here the results for the eight selected urban areas (see Fig. 5). The differences between CB05 and RACM2 in ozone concentrations simulated with only $\mathrm{NO}_{y}$ and $\mathrm{SO}_{x}$ emissions are about $10 \%$ in the urban areas considered here ( $9 \%$ for the monthly average 8 -h maximum averaged over the whole domain). This non-negligible difference is due primarily to differences in the oxidation reactions of $\mathrm{NO}$ by $\mathrm{O}_{3}$ and $\mathrm{HO}_{2}$. This result highlights the fact that uncertainties in the modeling of gas-phase chemistry are not solely due to the condensed representation of VOC but also results from uncertainties in the kinetics of key inorganic reactions. 


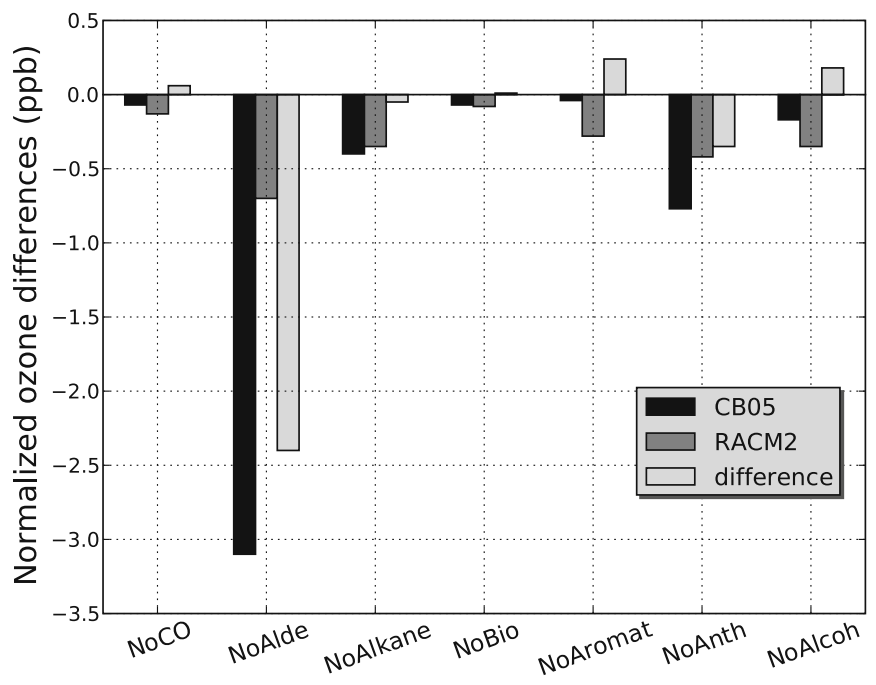

(a) Method 1

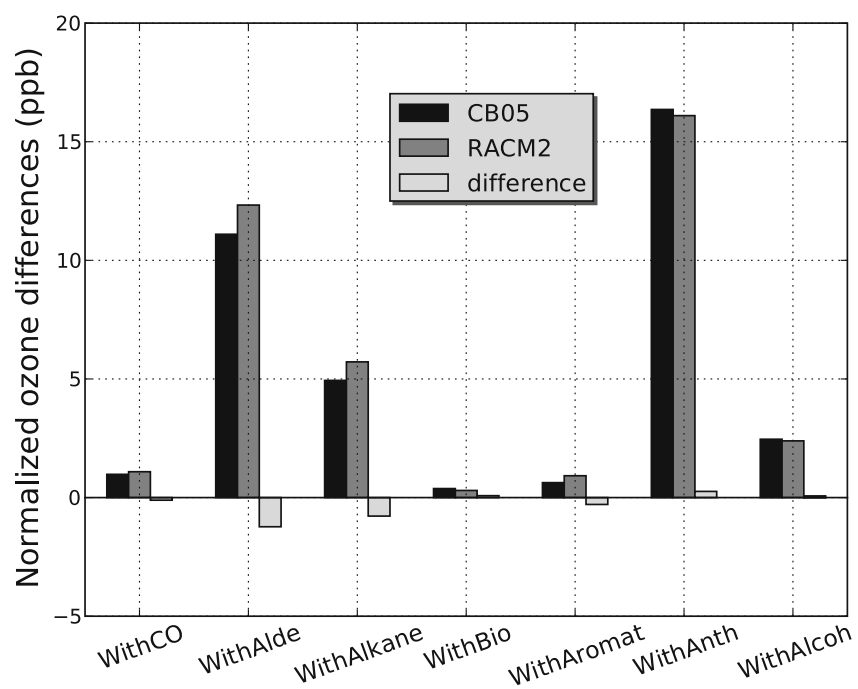

(b) Method 2

Fig. 8 Differences of the monthly-averaged daily maximum 8-h average ozone concentrations averaged over the entire domain ( $\mathrm{ppb}$ ) between the emission scenario case and the reference case normalized by the corresponding emission rate, and differences between the CB05 and RACM2 results

Differences of 8h-maximum ozone concentrations between the mechanisms occur for both methods 1 and 2 at all locations, ranging from 0.01 to $8.5 \mathrm{ppb}$. Figure 9 shows the different patterns in two cities representing $\mathrm{VOC}$-sensitive and $\mathrm{NO}_{x}$-sensitive chemistry, respectively : Paris and Madrid. From the Method 1 results in Paris, all categories of carbonaceous compounds contribute to ozone formation. In Madrid, 
the contribution of biogenic compounds to ozone formation is the most important and leads to a $\mathrm{NO}_{x}$-sensitive chemistry in that location (Sillman 1999).

With Method 2, for most cases the ozone amounts in RACM2 are higher than these in CB05; exceptions are alkanes and biogenic compounds. The most significant differences (1.5 to $8.5 \mathrm{ppb}$ ) occur in the WithCO and the WithAromatic cases. The kinetics of the oxidation of $\mathrm{CO}$ by $\mathrm{OH}$ is identical in CB05 and RACM2. However, as discussed above, the $\mathrm{O}_{3}$ concentrations due to $\mathrm{NO}_{x}$ chemistry differ and, as a

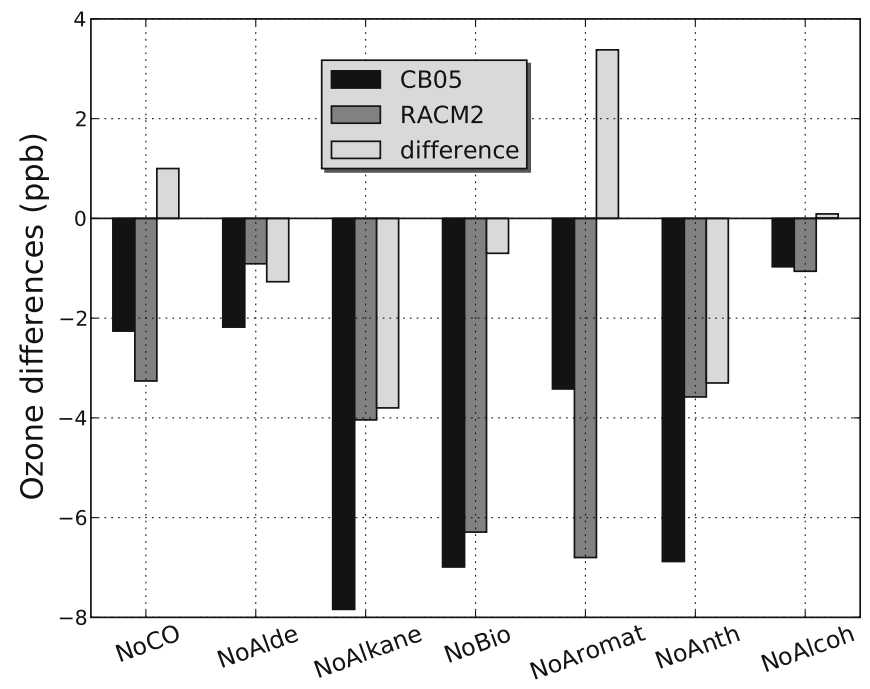

(a) Paris with Method 1

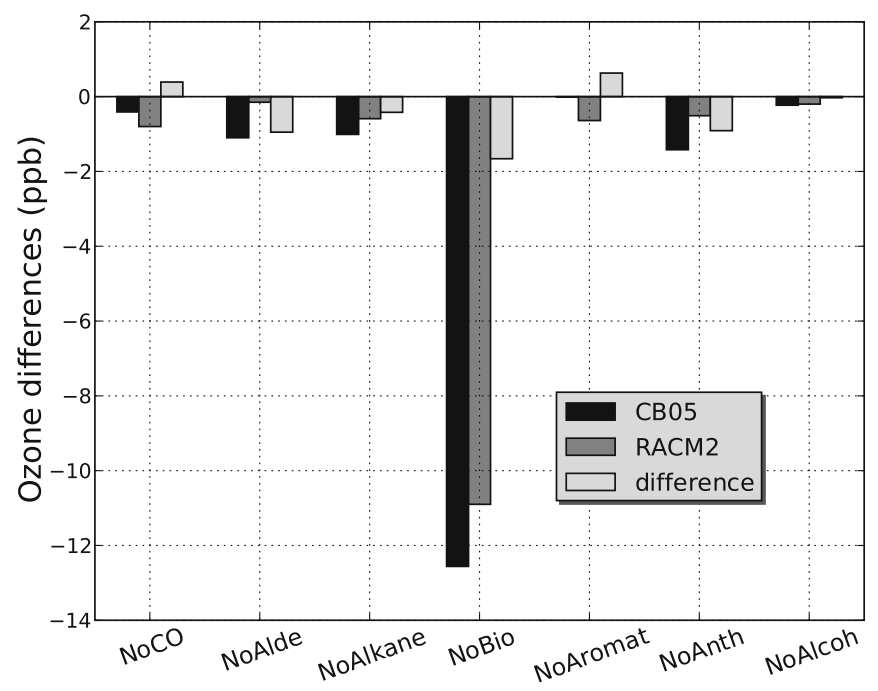

(b) Madrid with Method 1

Fig. 9 Different patterns of ozone differences in Paris and Madrid 


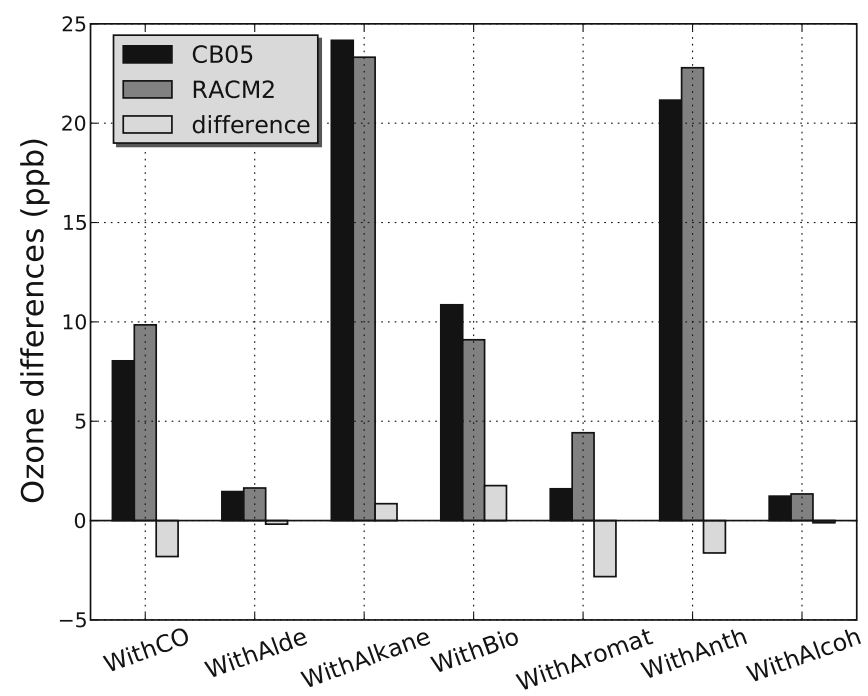

(c) Paris with Method 2

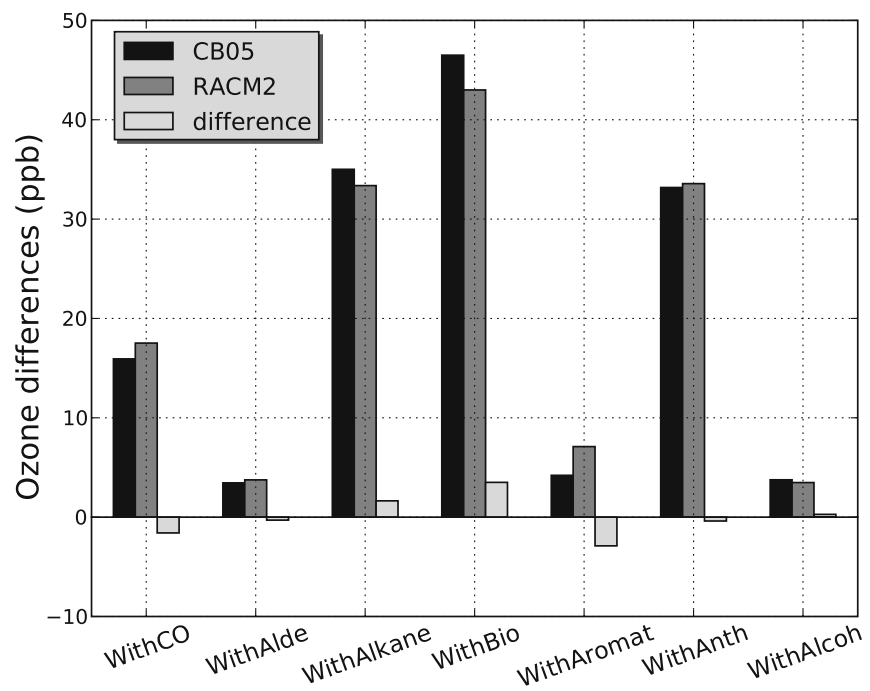

(d) Madrid with Method 2

Fig. 9 (continued)

result, the $\mathrm{OH}$ concentrations differ, thereby affecting the $\mathrm{CO}$ oxidation rate and subsequently, $\mathrm{O}_{3}$ formation. The $\mathrm{O}_{3}$ concentration differences in the WithCO case range from $10 \%$ in the southern urban area (Madrid, Barcelona and Roma) to $18 \%$ in northern urban areas. The aromatic-OH adduct reacts with $\mathrm{O}_{2}$ to either abstract an $\mathrm{H}$ atom to form a cresol (via the oxidation of toluene) or add $\mathrm{O}_{2}$ to form a peroxyl radical that subsequently leads to ring opening and the formation of scission products. Therefore, the cresol yield is a key element to differentiate the relative importance of these two pathways in chemical mechanisms. The experimental cresol 


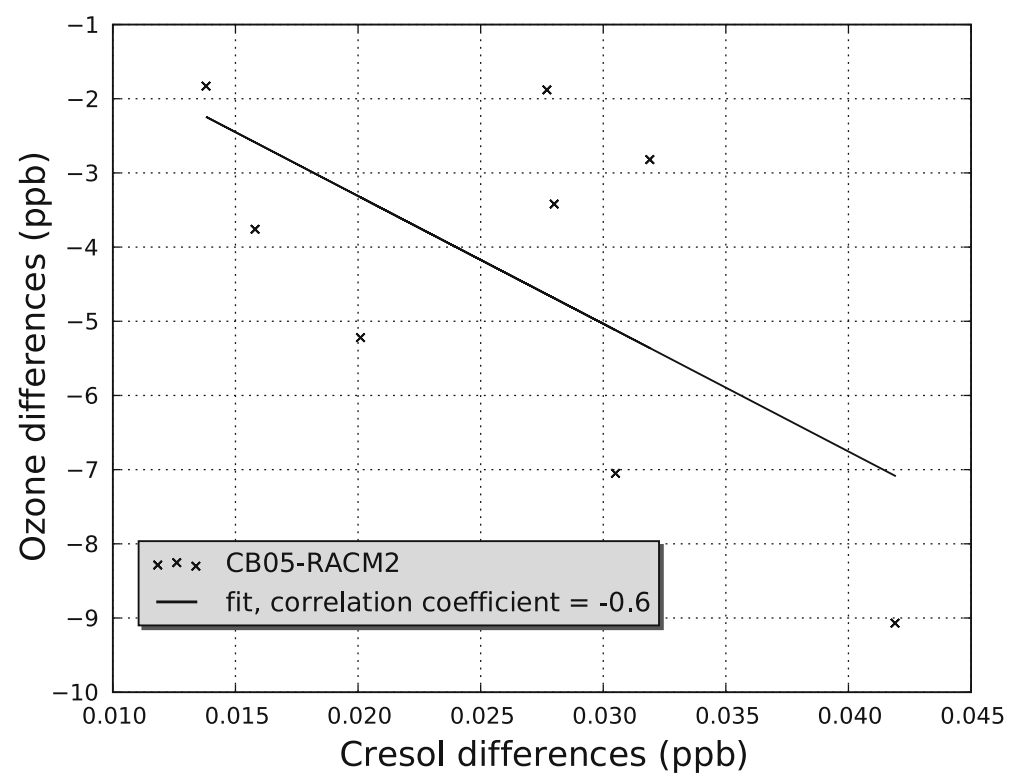

Fig. 10 Relation between the differences in cresol concentrations and ozone concentrations obtained with $\mathrm{CB} 05$ and RACM2 from the results of the eight urban areas

yield from the oxidation of toluene varies from $\leq 3 \%$ to $38 \%$ under different conditions, e.g., presence of $\mathrm{NO}_{x}$ and $\mathrm{H}_{2} \mathrm{O}_{2}$ (Calvert et al. 2002). Because of the discrepancy of the experimental results, assumptions about the importance of ringopening pathways for the toluene reactions with hydroxyl radical species differ among various mechanisms. RACM2 assumes that the majority of the reaction products are highly reactive species associated with ring-opening reactions (DCB2 and EPX). In contrast, CB05 has a high fraction of the ring-retaining products (CRES); therefore, aromatic oxidation products in RACM2 are more reactive than those in CB05 (Faraji et al. 2008; Luecken et al. 2008). These different pathways are the main cause of differences in ozone formation in the WithAromat case. To illustrate the influence of aromatics on ozone formation, Fig. 10 shows differences of monthly mean cresol concentration between the two mechanisms at the eight urban areas. The correlation coefficient between cresol concentrations and ozone concentrations implies that more cresol corresponds to less ozone formation.

Figure 11 displays the ozone differences between the two mechanisms for the eight urban areas for the WithAnthAlkene, NoAnthAlkene and WithBioAlkene cases. Both WithAnthAlkene and NoAnthAlkene cases (anthropogenic alkenes) lead to significant differences in ozone concentration between the two mechanisms. These differences are greater in the VOC-sensitive cities than in the $\mathrm{NO}_{x}$-sensitive cities for the two cases but it is opposite for the WithBioAlkene case. The treatment of anthropogenic alkenes differs significantly between the two mechanisms. For example, 1-butene is represented by 3 PAR + FORM in CB05 and by OLT in RACM2. Propene is represented by PAR + OLE in CBO5 and by OLT in RACM2. Ozone differences are greater in the four VOC-sensitive cities than in the others because $\mathrm{O}_{3}$ concentrations are more sensitive to VOC emissions in the former; 


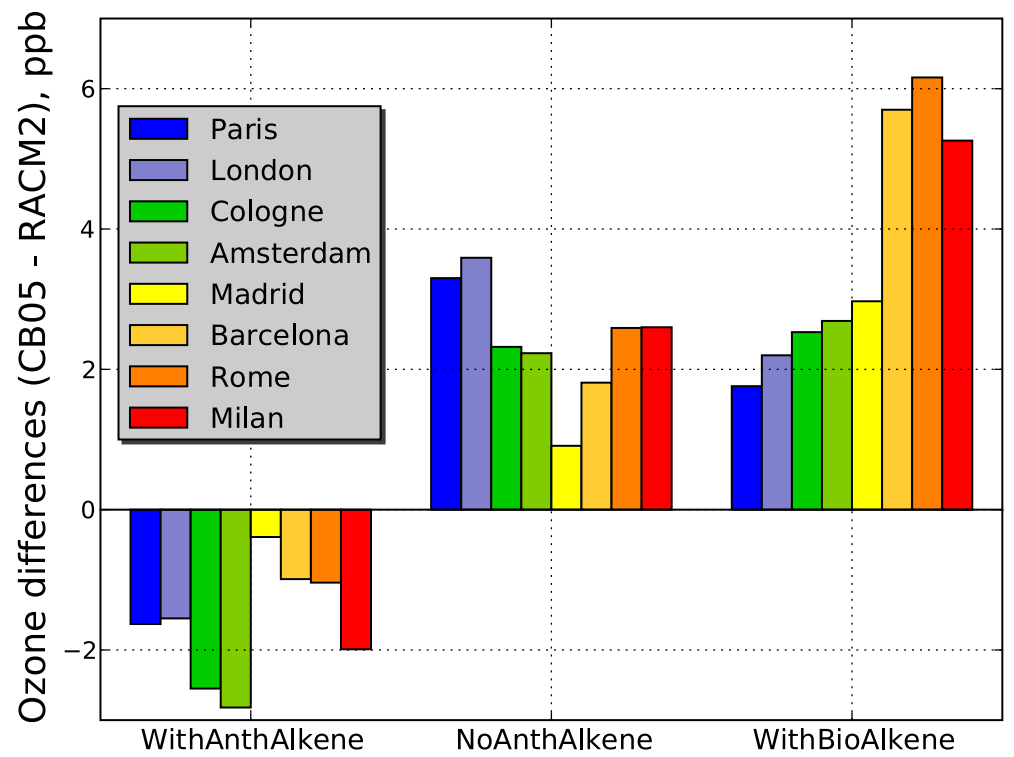

Fig. 11 Ozone differences between the two mechanisms for all eight urban areas in three cases: WithAnthAlkene, NoAnthAlkene and WithBioAlkene

furthermore, total carbon emission rates of anthropogenic alkenes in these VOCsensitive cities are higher than those in the four $\mathrm{NO}_{x}$-sensitive cities.

In the WithBioAlkene case, the influence on ozone concentration is greater in CB05 than in RACM2 (see Fig. 11). The difference between the two mechanisms varies from $1.8 \mathrm{ppb}$ (Paris) to $6.2 \mathrm{ppb}$ (Rome), and is explained by the different treatment of isoprene and monoterpenes. The kinetics for isoprene is identical in the two mechanisms but the primary isoprene products differ; CB05 includes one isoprene product (ISPD) but RACM2 includes methacrolein (MACR) and methyl vinyl ketone (MVK) as products. The rate constants for the reactions of ISPD and MACR with $\mathrm{OH}$ are identical at $298 \mathrm{~K}$, however, the rate constant for MVK is lower than that for ISPD. Thus, the ozone formation for isoprene is greater in CB05 than in RACM2. Similarly, CB05 includes only one terpene species (TERP) whereas RACM2 has a more detailed monoterpene mechanism with two terpene species (API and LIM). The oxidation of TERP in CB05 leads to more ozone formation over Europe than the oxidation of API and LIM in RACM2. The rate constant for the reaction of TERP with $\mathrm{OH}$ radicals falls between the two rate constants for the reactions of API and LIM with OH; i.e., $k_{A P I, O H}<k_{T E R P, O H}<k_{L I M, O H}$. However, the formation of the hydroperoxyl radicals and nitrogen dioxide by the oxidation with $\mathrm{OH}$ differs and the amount is about $15 \%$ higher in CB05 than in RACM2. Thus, CB05 leads to about $10 \%$ more ozone formation than RACM2 in the WithBioAlkene case. Locations with highly reactive VOC, e.g., xylenes or isoprene are more likely to have $\mathrm{NO}_{x}$-sensitive chemistry than locations with similar total VOC but lower reactivity (Sillman 1999; Hakami et al. 2004). The enhancement of ozone is mainly attributed to the evident increase in the peroxyl radicals $\left(\mathrm{HO}_{2}+\mathrm{RO}_{2}, \mathrm{RO}_{2}\right.$ representing all organic peroxyl radicals) by biogenic emissions 


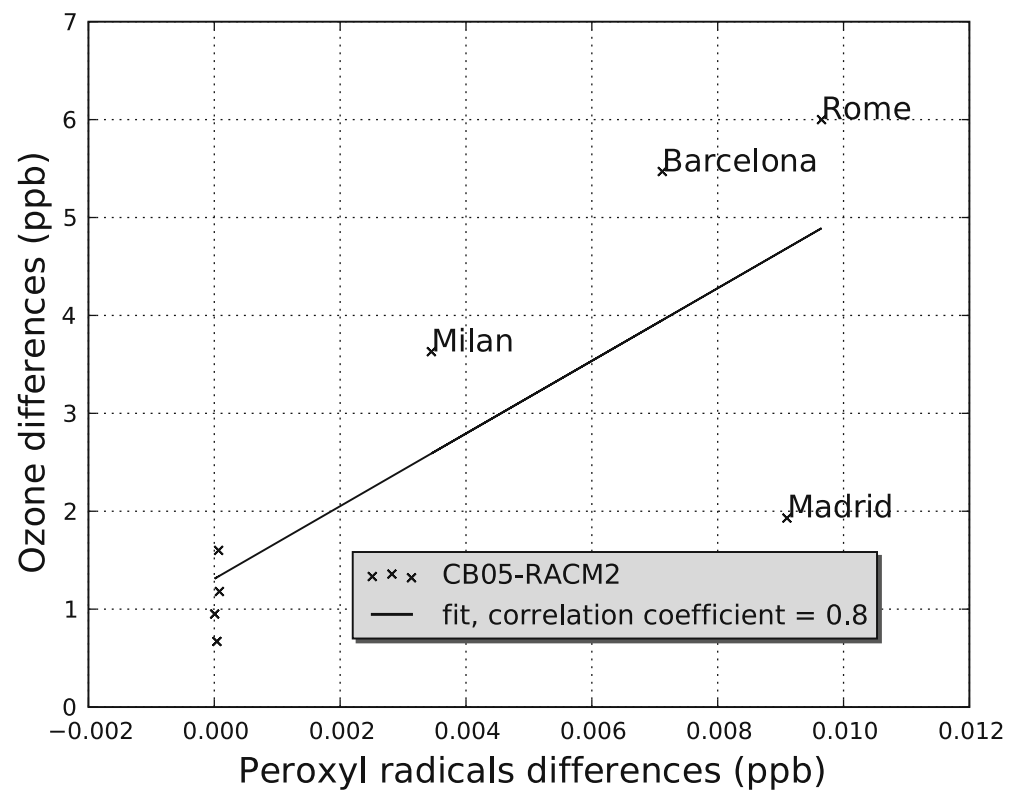

Fig. 12 Relation between the differences in peroxyl radicals concentrations and ozone concentrations obtained with CB05 and RACM2 in the eight urban areas for the case WithBioAlkene

(Han et al. 2005). Figure 12 illustrates the differences of $\mathrm{O}_{3}$ and peroxyl radicals in the eight cities selected. We find that the influence of biogenic emissions on ozone concentrations in the four cities (Madrid, Rome, Milan and Barcelona) classified $\mathrm{NO}_{x}$-sensitive in Fig. 3 is correlated with the peroxyl radicals. This result shows that those cities are $\mathrm{NO}_{x}$-sensitive because of the large biogenic emissions.

Alkanes are not very reactive chemical compounds at the urban scale compared with alkenes and aromatic compounds (Calvert et al. 2008). However, their emissions can be significant, $47 \%$ of anthropogenic VOCs over Europe. Differences are small for Method $2(<10 \%)$ but greater for Method 1 (about 50\%). Similarly, aldehydes show significant differences for Method 1 and negligible differences for Method 2. The difference in aldehyde chemistry is explained in part by the fact that some aldehyde species are explicitly represented in RACM2 with species that have greater reactivity than the surrogate functional groups of $\mathrm{CB} 05$. Benzaldehyde, methacrolein and glyoxal contribute 20,9 and $1 \%$ of total aldehyde emissions, respectively. Benzaldehyde is represented as BALD in RACM2, whereas it is aggregated with TOL in CB05. Methacrolein and glyoxal are explicitly represented in RACM2 as MACR and GLY, which have relatively high reactivities with $\mathrm{OH}$, whereas these two species are implicitly aggregated in CB05 as OLE + ALDX and PAR + FORM, which have lower reactivities with $\mathrm{OH}$.

\subsubsection{Remote areas}

We compare CB05 and RACM2 for the four remote locations indicated in Fig. 3. Both Fontainebleau and the Algerian coastal location (ACL hereafter) show similar moderate ozone concentrations (61 to $65 \mathrm{ppb}$ ); however, the ozone difference 
between the two mechanisms is high at ACL but low at Fontainebleau. ACL clearly has $\mathrm{NO}_{x}$-sensitive chemistry but the chemical regime at Fontainebleau is mixedchemistry. This is due to the transport of $\mathrm{NO}_{x}$ emissions from Paris. For the WithBioAlkene case, the ozone concentration with $\mathrm{CB} 05$ is up to 12.5 ppb greater than
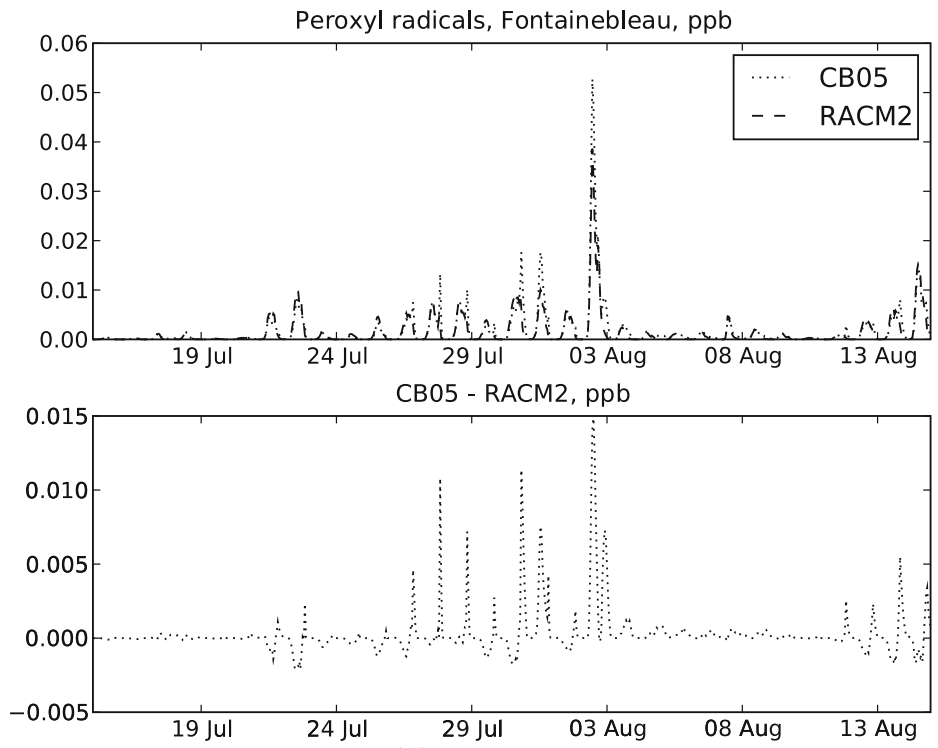

(a) Fontainebleau

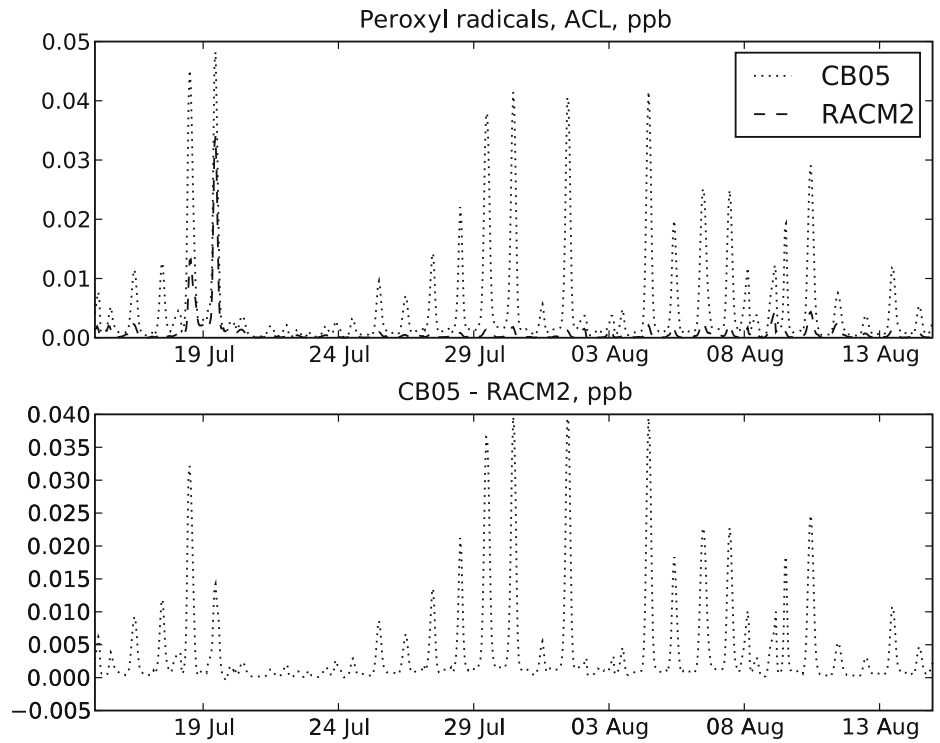

(b) Algerian coastal location

Fig. 13 Temporal differences of peroxyl radicals between CB05 and RACM2 at Fontainebleau and ACL, WithBioAlkene case 
that with RACM2 at ACL. As mentioned above, this difference due to the biogenic emissions can be explained by the enhancement of the peroxyl radicals in CB05 (average differences between the mechanisms of $2.8 \times 10^{-4} \mathrm{ppb}$ at Fontainebleau, $3.8 \times 10^{-3} \mathrm{ppb}$ at ACL, see Fig. 13). At the other two locations, Gulf of Taranto and Ligurian Sea, where $\mathrm{O}_{3}$ concentrations are rather high ( $\left.>75 \mathrm{ppb}\right), \mathrm{RACM} 2$ predicts more ozone than CB05 in the Gulf of Taranto but the two mechanisms predict the same ozone concentration in the Ligurian Sea. In the Ligurian Sea, CB05 leads to more ozone formation than RACM2 in the WithAlkane case (5.8 ppb) and WithBioAlkene case (12.2 ppb). On the contrary, RACM2 leads to more ozone formation than CB05 in the WithCO case (2.8 ppb), the WithAromat case (4.4 ppb), and the WithAnthAlkene case (1.8 ppb). These results show that the greater ozone formation from alkanes and biogenic alkenes in CB05 is compensated by the lower ozone formation from the other VOC. However, in the Gulf of Taranto, RACM2 leads to more ozone formation than CB05 and the ozone concentration in RACM2 from the AllEmis case is $4 \mathrm{ppb}$ greater than that in CB05. CB05 leads to more ozone formation than RACM2 in the WithAlkane (2.9 ppb) and the WithBioAlkene (4.2 ppb) cases but RACM2 leads to more ozone formation in the WithCO (2 ppb), the WithAromat (2.8 ppb) and the WithAnthAlkene (0.9 ppb) cases. These results show that the oxidation of the biogenic emissions in the Gulf of Taranto is weaker than in the Ligurian Sea.

Finally, ACL and the Gulf of Taranto where large differences between the two mechanisms are observed, differ by the amount of ozone formation in the WithBioAlkene case (see Fig. 14). When all emissions are considered, the $\mathrm{O}_{3}$ concentration is greater with CB05 than with RACM2 (3.5 ppb) at ACL, but it is

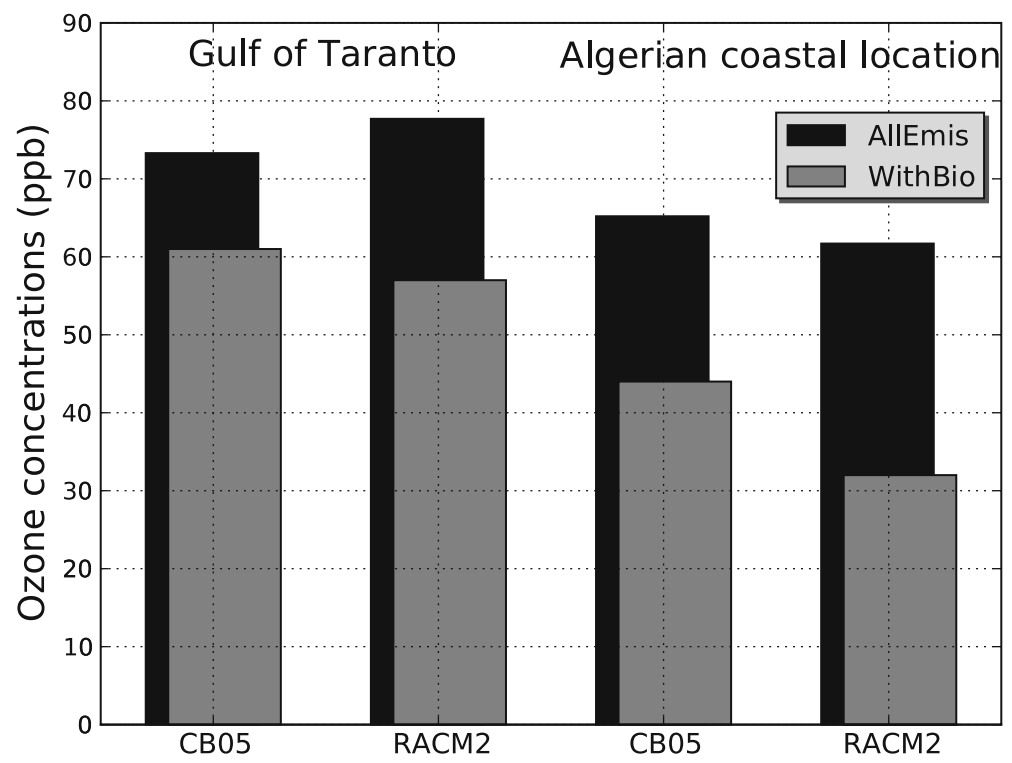

Fig. 14 Ozone concentrations with WithBioAlkene and AllEmis cases at the Gulf of Taranto and ACL 
the opposite (4.4 ppb) at the Gulf of Taranto. There is greater ozone formation with CB05 than with RACM2 at ACL because of higher biogenic emissions (see above for the cause of greater reactivity of biogenic VOC with CB05).

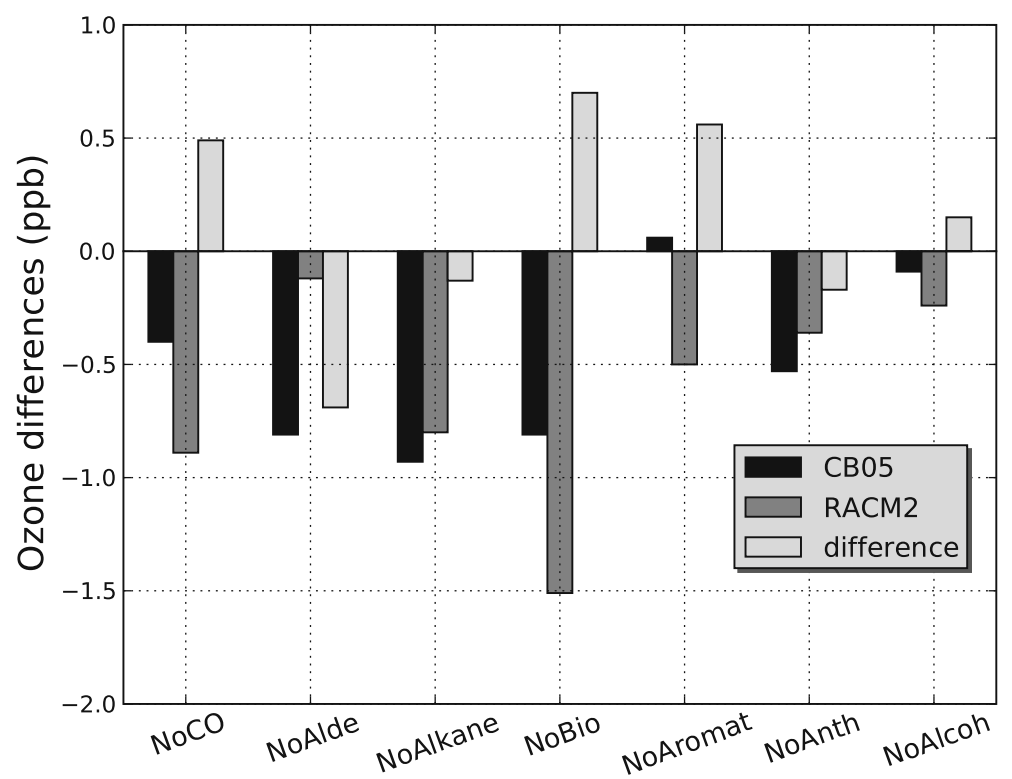

(a) Method 1

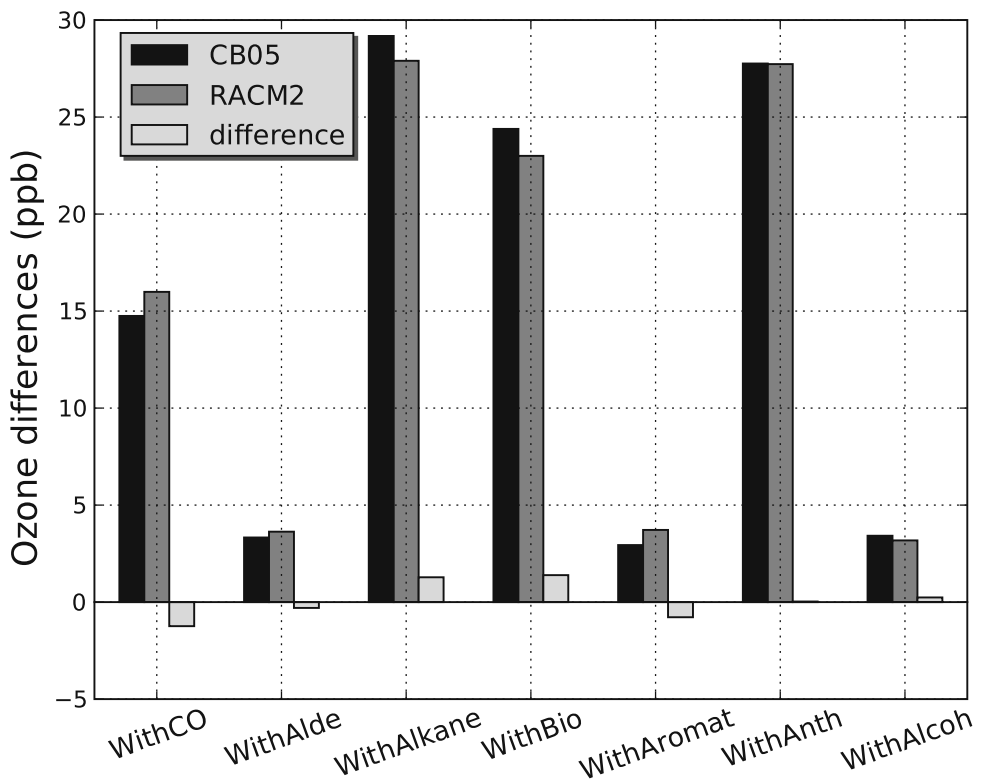

(b) Method 2

Fig. 15 8h-maximum ozone differences (ppb) between CB05 and RAMC2 at the Bio 1 location in the Iberian Peninsula 


\subsubsection{Locations with high biogenic emissions}

Small differences (0.03 to $1.86 \mathrm{ppb})$ between the two chemical mechanisms are obtained at the locations where the biogenic emission rates are high (see Figs. 1c and 5). This is due to a strong $\mathrm{NO}_{x}$-sensitive chemistry in that region. Despite these weak differences, some cases are of interest to analyze. The NoAromat case of Method 1 shows slightly increased $\mathrm{O}_{3}$ concentration with regard to the AllEmis case only with the CB05 mechanism (0.06 to $0.18 \mathrm{ppb}$ ). As we mentioned before, the major product of the oxidation of aromatic chemical compounds in CB05 is cresol. Hence, fewer aromatic compounds cause lower amounts of cresols and allow other VOC to be oxidized by more $\mathrm{OH}$ resulting in more ozone formation. For Method 2, ozone concentrations with CB05 are higher than those with RACM2 in the WithAlkane and the WithBioAlkene cases, similar to what was obtained at the four $\mathrm{NO}_{x}$-sensitive cities. Figure 13 displays differences of $8 \mathrm{~h}$-maximum ozone between the two mechanisms at one of these locations.

When only biogenic emissions are considered, i.e., without all anthropogenic VOC and $\mathrm{NO}_{x}$, the modeled ozone concentrations remain near background levels in any area of the Iberian Peninsula, because the biogenic emission contribution to ozone formation requires interaction with anthropogenic emissions (Castell et al. 2008). This interaction differs between CB05 and RACM2 in the Iberian Peninsula. In the NoBioAlkene case, the decrease in ozone from the reference case is significantly greater in RACM2 than in CB05. The ozone difference between the two mechanisms does not seem significant in the WithBioAlkene case; although it is comparable in absolute concentration $(\sim 1 \mathrm{ppb})$ to that obtained in the NoBioAlkene case. However, the effect is reversed with RACM2 contributing more ozone when all emissions are considered and CB05 contributing more ozone when only biogenic emissions are considered (Fig. 15).

\section{Conclusion}

The comparison of the two chemical mechanisms was conducted by species categories including non-carbonaceous species (i.e., nitrogen and sulfur oxides), CO, alkanes, anthropogenic alkenes, aromatics, aldehydes, alcohols and biogenic VOC. Overall, the two mechanisms show similar ozone spatial patterns and domainaveraged concentrations (difference of only $3 \mathrm{ppb}$ or $5 \%$ ). This result is consistent with earlier comparisons conducted for other mechanisms where differences ranged from less than $1 \%$ to $8 \%$. Significant differences, however, appear at specific locations and/or for specific chemical species categories.

Uncertainties in the kinetics of two key inorganic reactions, $\mathrm{NO}+\mathrm{O}_{3} \longrightarrow \mathrm{NO}_{2}+$ $\mathrm{O}_{2}$ and $\mathrm{NO}+\mathrm{HO}_{2} \longrightarrow \mathrm{NO}_{2}+\mathrm{OH}$, lead to non-negligible differences in oxidant concentrations (mean fractional absolute difference of $5 \%$ over the whole domain). When analyzing ozone differences by categories of carbonaceous species ( $\mathrm{CO}$ and VOC classes), the largest differences occur for $\mathrm{CO}$ and aromatics due in part to the large contributions of their emissions to the total inventory. When differences in ozone concentrations are normalized by the corresponding VOC emissions, significant differences appear also due to the chemistry of aldehydes, anthropogenic alkenes and alkanes. Differences in the treatment of biogenics have a significant effect in areas with large biogenic emissions. 
Diagnostic analyses lead to the following conclusions. Although the CO chemical kinetics is identical in the two mechanisms, different $\mathrm{OH}$ concentrations due to uncertainties in nitrogen chemistry lead to significant differences in ozone formation from CO emissions. Differences in the contribution of aromatics to ozone formation are due mostly to the fact that aromatics oxidation in RACM2 leads to more ringopening products than in CB05, which favors the formation of aromatic alcohols (e.g., cresol formation from toluene oxidation). The former products being more reactive, RACM2 aromatics chemistry leads to more ozone formation than CB05.

The differences in aldehyde and biogenics chemistry are due to the more detailed treatment in RACM2 where several surrogate molecules are used to characterize the products. The assumptions made in the two mechanisms lead to more reactivity of aldehydes in RACM2 but more reactivity of biogenics in CB05.

Differences in the chemistry of alkanes and anthropogenic alkenes result primarily from the fundamental representations of those VOC categories in the two mechanisms: lumped structure versus lumped molecules. Approximations are necessary in both approaches and they translate into differences in ozone formation. Those differences, however, are not larger than those obtained for other parts of the mechanisms, which suggests that the lumped representations have been optimized to the extent possible.

The results obtained in this comparison of two recent gas-phase chemical mechanisms for ozone formation are encouraging because (1) the differences are small on average and (2) the differences identified for specific chemical categories are due mostly to uncertainties in our knowledge of the chemistry (e.g., kinetics of NO oxidation reactions, relative importance of chemical pathways for aromatics oxidation). Differences in the approximations needed to condense the VOC chemistry (i.e., lumped structures or lumped molecules) do not contribute more to the overall uncertainties than those other factors. Therefore, future improvements in gas-phase chemical kinetic mechanisms will require experimental data to reduce current uncertainties. Those improvements are likely to benefit both lumped-structure and lumped-molecule mechanisms as both appear to be able to represent ozone chemistry satisfactorily.

Acknowledgements We thank Deborah Luecken (U.S. Environmental Protection Agency) for helpful discussions about CB05 mechanism. We also thank Wendy Goliff (University of California, Riverside) for providing us RACM2 mechanism and for useful discussions about the mechanism.

Open Access This article is distributed under the terms of the Creative Commons Attribution Noncommercial License which permits any noncommercial use, distribution, and reproduction in any medium, provided the original author(s) and source are credited.

\section{References}

Arteta, J., Cautenet, S., Taghavi, M., Audiffren, N.: Impact of two chemistry mechanisms fully coupled with mesoscale model on the atmospheric pollutants distribution. Atmos. Environ. 40, 7983-8001 (2006) doi:10.1016/j.atmosenv.2006.06.050

Atkinson, R., Baulch, D.L., Cox, R.A., Crowley, J.N., Hampson, R.F., Hynes, R.G., Jenkin, M.E., Rossi, M.J., Troe, J.: Evaluated kinetic and photochemical data for atmospheric chemistry IUPAC subcommittee on gas kinetic data evaluation for atmospheric chemistry, available at: http://www.iupac-kinetic.ch.cam.ac.uk (2005) 
Atkinson, R., Baulch, D.L., Cox, R.A., Crowley, J.N., Hampson, R.F., Hynes, R.G., Jenkin, M.E., Rossi, M.J., Troe, J.: Evaluated kinetic and photochemical data for atmospheric chemistry IUPAC subcommittee on gas kinetic data evaluation for atmospheric chemistry, available at: http://www.iupac-kinetic.ch.cam.ac.uk (2006)

Aumont, B., Szopa, S., Madronich, S.: Modelling the evolution of organic carbon during its gas-phase tropospheric oxidation: development of an explicit model based on a self generating approach. Atmos. Chem. Phys. 5, 2497-2517 (2005)

Bloss, C., Wagner, V., Jenkin, M.E., Volkamer, R., Bloss, W.J., Lee, J.D., Heard, D.E., Wirtz, K., Martin-Reviejo, M., Rea, G., Wenger, J.C., Pilling, M.J.: Development of a detailed chemical mechanism (MCMv3.1) for the atmospheric oxidation of aromatic hydrocarbons. Atmos. Chem. Phys. 5, 641-664 (2005) available at: http://mcm.leeds.ac.uk/MCM

Bowman, F.M., Pilinis, C., Seinfeld, J.H.: Ozone and aerosol productivity of reactive organics. Atmos. Environ. 29, 579-589 (1995) doi:10.1016/1352-2310(94)00283-Q

Calvert, J.G., Atkinson, R., Becker, K.H., Kamens, R.M., Seinfeld, J.H., Wallington, T.J., Yarwood, G.: The Mechanisms of Atmospheric Oxidation of Aromatic Hydrocarbons, pp. 83-87. Oxford University Press, New York (2002)

Calvert, J.G., Derwent, R.G., Orlando, J.J., Tyndall, G.S., Wallington, T.J.: Mechanisms of Atmospheric Oxidation of the Alkanes, pp. 8-13. Oxford University Press, New York (2008)

Carter, W.P.L.: Computer modeling of environmental chamber measurements of maximum incremental reactivities of volatile organic compounds. Atmos. Environ. 29, 2513-2527 (1995) doi:10.1016/1352-2310(95)00150-W

Carter, W.P.L.: Development of an improved chemical speciation database for processing emissions of volatile organic compounds for air quality models, available at: http://www.engr.ucr.edu/ carter/emitdb (2008)

Carter, W.P.L., Pierce, J.A., Dongmin, L., Malkina, I.L.: Environmental chamber study of maximum incremental reactivities of volatile organic compounds. Atmos. Environ. 29 2499-2511 (1995) doi:10.1016/1352-2310(95)00149-S

Castell, N., Stein, A.F., Salvador, R., Mantilla, E., Millán, M.: The impact of biogenic VOC emissions on photochemical ozone formation during a high ozone pollution episode in the Iberian Peninsula in the 2003 summer season. Adv. Sci. Res. 2, 9-15 (2008)

Curci, G., Beekmann, M., Vautard, R., Smiatek, G., Steinbrecher, R., Theloke, J., Friedrich, R.: Modelling study of the impact of isoprene and terpene biogenic emissions on European ozone levels. Atmos. Environ. 43, 1444-1455 (2009) doi:10.1016/j.atmosenv.2008.02.070

Dennis, R.L., Byun, D.W., Novak, J.H., Galluppi, K.J., Coats, C.J., Vouk, M.A.: The next generation of integrated air quality modeling: EPA's Models-3. Atmos. Environ. 30, 1925-1938 (1996) doi:10.1016/1352-2310(95)00174-3

Derwent, R.G., Jenkin, M.E., Passant, N.R., Pilling, M.J.: Reactivity-based strategies for photochemical ozone control in Europe. Environ. Sci. Policy 10 445-453 (2007) doi:10.1016/j.envsci. 2007.01.005

Djouad, R., Sportisse, B., Audiffren, N.: Numerical simulation of aqueous-phase atmospheric models: use of a non-autonomous Rosenbrock method. Atmos. Environ. 36, 873-879 (2002) doi:10.1016/S1352-2310(01)00497-6

Dodge, M.C.: Chemical oxidant mechanisms for air quality modeling: critical review. Atmos. Environ. 34, 2103-2130 (2000)

Dommen, J., Prévôt, A., Neininger, B., Bäumle, M.: Characterization of the photooxidant formation in the metropolitan area of Milan from aircraft measurements. J. Geophys. Res. 107, 8197 (2002) doi:10.1029/2000JD000283

Faraji, M., Kimura, Y., McDonald-Buller, E., Allen, D.: Comparison of the Carbon Bond and SAPRC photochemical mechanisms under conditions relevant to southeast Texas. Atmos. Environ. 42, 5821-5836 (2008) doi:10.1016/j.atmosenv.2007.07.048

Finlayson-Pitts, B.J., Pitts, J.N. Jr: Chemistry of the upper and lower atmosphere, Academic Press, San Diego (2000)

Gery, M.W., Whitten, G.Z., Killus, J.P., Dodge, M.C.: A photochemical kinetics mechanism for urban and regional scale computer modeling. J. Geophys. Res. 94(D10), 12 925-12 956 (1989)

Goliff, W.S., Stockwell, W.R.: The Regional Atmospheric Chemistry Mechanism, version 2, an update, International Conference on Atmospheric Chemical Mechanisms, University of California at Davis, available at: http://airquality.ucdavis.edu/pages/events/2008/acm/Goliff.pdf (2008)

Goliff, W.S., Stockwell, W.R.: The Regional Atmospheric Chemistry Mechanism, version 2. 1. Description and Evaluation, in preparation, to be submitted to J. Geophys. Res. (2009) 
Hakami, A., Bergin, M.S., Russell, A.G.: Ozone formation potential of organic compounds in the eastern United States: A comparison of episodes, inventories, and domains. Environ. Sci. Technol. 38, 6748-6759 (2004) doi:10.1021/es035471a

Han, Z., Ueda, H., Matsuda, K.: Model study of the impact of biogenic emission on regional ozone and the effectiveness of emission reduction scenarios over eastern China. Tellus B 57, 12-27 (2005) doi:10.1111/j.1600-0889.2005.00132.x

Honoré, C., Vautard, R., Beekmann, M.: Photochemical regimes in urban atmospheres: The influence of dispersion. Geophys. Res. Lett. 27(13), 1895-1898 (2000)

Honoré, C., Rouill, L., Vautard, R., Beekmann, M., Bessagnet, B., Dufour, A., Elichegaray, C., Flaud, J.-M., Malherbe, L., Meleux, F., Menut, L., Martin, D., Peuch, A., Peuch, V.-H., Poisson, N.: Predictability of European air quality: Assessment of 3 years of operational forecasts and analyses by the PREV'AIR system. J. Geophys. Res. 113, D04 301 (2008)

Johnson, D., Utembe, S.R., Jenkin, M.E., Derwent, R.G., Hayman, G.D., Alfarra, M.R., Coe, H., McFiggans, G.: Simulating regional scale secondary organic aerosol formation during the TORCH 2003 campaign in the southern UK. Atmos. Chem. Phys. 6, 403-418 (2006)

Junier, M., Kirchner, F., Clappier, A., van den Bergh, H.: The chemical mechanism generation programme CHEMATA-Part 2: Comparison of four chemical mechanisms for mesoscale calculation of atmospheric pollution. Atmos. Environ. 39, 1161-1171 (2005) doi:10.1016/j.atmosenv. 2004.09.085

Kuebler, J., Giovannoni, J.M., Russell, A.G.: Eulerian modeling of photochemical pollutants over the Swiss Plateau and control strategy analysis. Atmos. Environ. 30, 951-966 (1996) doi:10.1016/1352-2310(95)00306-1

Kuhn, M., Builtjes, P.J.H., Poppe, D., Simpson, D., Stockwell, W.R., Andersson-Skold, Y., Baart, A., Das, M., Fiedler, F., Hov, O., Kirchner, F., Makar, P.A., Milford, J.B., Roemer, M.G.M., Ruhnke, R., Strand, A., Vogel, B., Vogel, H.: Intercomparison of the gas-phase chemistry in several chemistry and transport models. Atmos. Environ. 32, 693-709 (1998) doi:10.1016/S13522310(97)00329-4

Louis, J.-F.: A parametric model of vertical eddy fluxes in the atmosphere. Bound.-Lay. Meteorol. 17, 187-202 (1979) doi:10.1007/BF00117978

Luecken, D.J.: Comparison of atmospheric chemical mechanisms for regulatory and research applications, pp. 95-106. Springer, Netherlands (2008) doi:10.1007/978-1-4020-8846-9_8

Luecken, D.J., Phillips, S., Sarwar, G., Jang, C.: Effects of using the CB05 vs. SAPRC99 vs. CB4 chemical mechanism on model predictions: Ozone and gas-phase photochemical precursor concentrations. Atmos. Environ. 42, 5805-5820 (2008) doi:10.1016/j.atmosenv.2007.08.056

Mallet, V., Quélo, D., Sportisse, B., Ahmed de Biasi, M., Debry, É., Korsakissok, I., Wu, L., Roustan, Y., Sartelet, K., Tombette, M., Foudhil, H.: Technical Note: The air quality modeling system Polyphemus. Atmos. Chem. Phys. 7, 5479-5487 (2007)

Martien, P.T., Harley, R.A., Milford, J.B., Russell, A.G.: Evaluation of incremental reactivity and its uncertainty in southern California. Environ. Sci. Technol. 37(8), 1598-1608 (2003) doi:10.1021/es026174t

Menut, L., Vautard, R., Beekmann, M., Honoré, C.: Sensitivity of photochemical pollution using the adjoint of a simplified chemistry-transport model. J. Geophys. Res. 105(D12), 15 379-15 402 (2000)

Pan, Y., Zhang, Y., Sarwar, G.: Impact of gas-phase chemistry on WRF/CHEM predictions of $\mathrm{O}_{3}$ and $\mathrm{PM}_{2.5}$ : Mechanism implementation and comparative evaluation, 7th annual CMAS conference, Chapel Hill, North Carolina, available at: http:/www.cmascenter.org/conference/2008/ abstracts/pan_impact_gas-phase_cmas08.pdf (2008)

Passant, N.: Speciation of UK emissions of NMVOC, AEA Technology, AEAT/ENV/0545 (2002)

Russell, A., Dennis, R.: NARSTO critical review of photochemical models and modeling. Atmos. Environ. 34, 2283-2324 (2000) doi:10.1016/S1352-2310(99)00468-9

Sander, S.P., Friedl, R.R., Golden, D.M., Kurylo, M.J., Huie, R.E., Orkin, V.L., Moortgat, G.K., Ravishankara, A.R., Kolb, C.E., Molina, M.J., Finlayson-Pitts, B.J.: Chemical kinetics and photochemical data for use in atmospheric studies, evaluation number 14, NASA Jet Propulsion Laboratory, available at: http://jpldataeval.jpl.nasa.gov/previous_evaluations.html (2003)

Sander, S.P., Friedl, R.R., Golden, D.M., Kurylo, M.J., Moortgat, G.K., Keller-Rudek, H., Wine, P.H., Ravishankara, A.R., Kolb, C.E., Molina, M.J., Finlayson-Pitts, B.J., Huie, R.E., Orkin, V.L.: Chemical kinetics and photochemical data for use in atmospheric studies, evaluation number 15, NASA Jet Propulsion Laboratory, available at: http://jpldataeval.jpl.nasa.gov/ download.html (2006) 
Sartelet, K.N., Debry, É., Fahey, K., Roustan, Y., Tombette, M., Sportisse, B.: Simulation of aerosols and gas-phase species over Europe with the Polyphemus system: Part I-Model-to-data comparison for 2001. Atmos. Environ. 41, 6116-6131 (2007) doi:10.1016/j.atmosenv.2007.04.024

Sarwar, G., Luecken, D., Yarwood, G., Whitten, G.Z., Carter, W.P.L.: Impact of an updated carbon bond mechanism on predictions from the CMAQ modeling system: Preliminary assessment. J. Appl. Meteor. Climatol. 47, 3-14 (2008)

Seinfeld, J., Pandis, S.: Atmospheric Chemistry and Physics: From Air Pollution to Climate Change, Wiley-Interscience, New York (1998)

Sillman, S.: The relation between ozone, $\mathrm{NO}_{x}$ and hydrocarbons in urban and polluted rural environments. Atmos. Environ. 33, 1821-1845 (1999) doi:10.1016/S1352-2310(98)00345-8

Sillman, S., He, D.: Some theoretical results concerning $\mathrm{O}_{3}-\mathrm{NO}_{x}$-VOC chemistry and $\mathrm{NO}_{x}$-VOC indicators. J. Geophys. Res. 107, 4659 (2002) doi:10.1029/2001JD001123

Sillman, S., Vautard, R., Menut, L., Kley, D.: $\mathrm{O}_{3}-\mathrm{NO}_{x}$-VOC sensitivity and $\mathrm{NO}_{x}$-VOC indicators in Paris: Results from models and atmospheric pollution over the Paris area (ESQUIF) measurements. J. Geophys. Res. 108(D17), (2003) doi:10.1029/2002JD001561

Simpson, D., Winiwarter, W., Börjesson, G., Cinderby, S., Ferreiro, A., Guenther, A., Hewitt, C.N., Janson, R., Aslam, M., Khalil, K., Owen, S., Pierce, T.E., Puxbaum, H., Shearer, M., Skiba, U., Steinbrecher, R., Tarrasón, L., Öquist, M.G.: Inventorying emissions from nature in Europe. J. Geophys. Res. 104, 8113-8152 (1999)

Sportisse, B.: Pollution atmosphérique: des processus à la modélisation, pp. 191-196. Springer-Verlag France, Paris (2008)

Stockwell, W.R.: Peer review of the SAPRC-07 chemical mechanism of Dr. William Carter, California Air Resources Board available at: http://www.arb.ca.gov/research/reactivity/3-25-2009/ stockwell-present.pdf (2009)

Stockwell, W.R., Kirchner, F., Kuhn, M., Seefeld, S.: A new mechanism for regional atmospheric chemistry modeling. J. Geophys. Res. 102, 25 847-25 879 (1997)

Troen, I.B., Mahrt, L.: A simple model of the atmospheric boundary layer; sensitivity to surface evaporation. Bound.-Lay. Meteorol. 37, 129-148 (1986) doi:10.1007/BF00122760

Tulet, P., Crassier, V., Rosset, R.: Air pollution modelling at a regional scale. Environ. Modell. Softw. 15, 693-701 (2000)

van Loon, M., Vautard, R., Schaap, M., Bergström, R., Bessagnet, B., Brandt, J., Builtjes, P.J.H., Christensen, J.H., Cuvelier, C., Graff, A., Jonson, J.E., Krol, M., Langner, J., Roberts, P., Rouil, L., Stern, R., Tarrasón, L., Thunis, P., Vignati, E., White, L., Wind, P.: Evaluation of long-term ozone simulations from seven regional air quality models and their ensemble. Atmos. Environ. 41, 2083-2097 (2007) doi:10.1016/j.atmosenv.2006.10.073

Wild, O., Zhu, X., Prather, M.J.: Fast-J: Accurate simulation of in- and below-cloud photolysis in tropospheric chemical models. J. Atmos. Chem. 37, 245-282 (2000) doi:10.1023/A:1006415919030

Yarwood, G., Rao, S., Yocke, M., Whitten, G.: Updates to the Carbon Bond Chemical Mechanism: CB05 Final Report to the US EPA, RT-0400675, available at: http://www.camx.com/publ/ pdfs/CB05_Final_Report_120805.pdf (2005)

Zhang, L., Moran, M.D., Makar, P.A., Brook, J.R., Gong, S.: Modelling gaseous dry deposition in AURAMS: a unified regional air-quality modelling system. Atmos. Environ. 36, 537-560 (2002) doi:10.1016/S1352-2310(01)00447-2

Zhang, Y., Vijayaraghavan, K., Seigneur, C.: Evaluation of three probing techniques in a threedimensional air quality model. J. Geophys. Res. 110, (2005) doi:10.1029/2004JD005248 